\title{
Giant ants and their shape: Revealing relationships in the genus Titanomyrma with Geometric Morphometrics
}

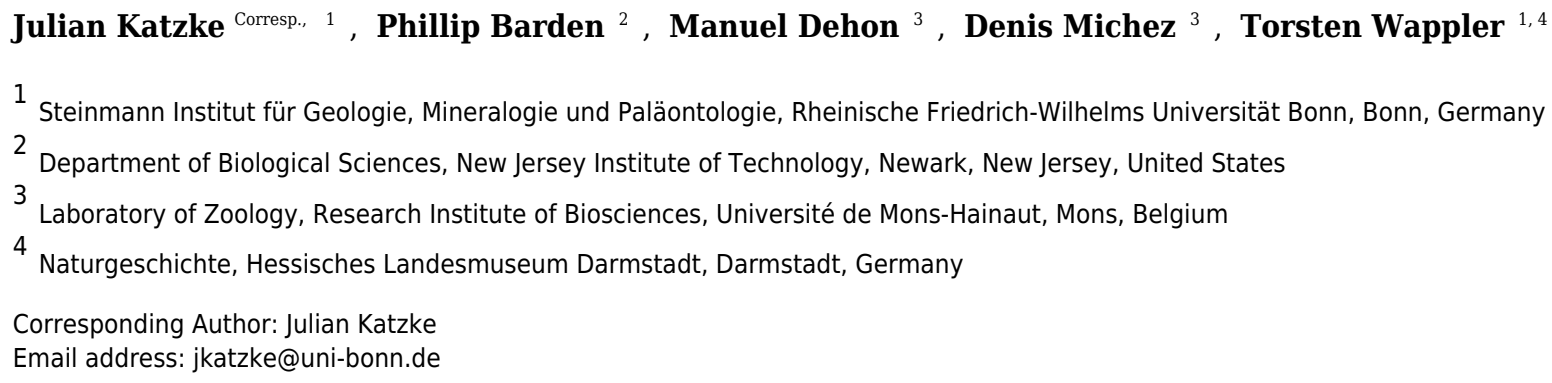

Shape is a natural phenomenon inherent to many different lifeforms. A modern technique to analyse shape is geometric morphometrics, which offers a whole range of methods concerning the pure shape of an object. The results from these methods have provided new insights into biological problems and have become especially useful in the fields of entomology and palaeontology. Despite the conspicuous successes in other hymenopteran groups, geometric morphometric analysis of wings and fossil wings of Formicidae has been neglected. Here we tested if landmarks defining the wing shape of fossil ants that belong to the genus Titanomyrma are reliable and if this technique is able to expose relationships among different groups of the largest Hymenoptera that ever lived. This study comprises 402 wings from 362 ants that were analysed and assigned with the geometric morphometric methods LDA, PCA, CVA, and regression. The giant ant genus Titanomyrma and the parataxon Formicium have different representatives that are all very similar but these modern methods were able to distinguish giant ant types even to the level of the sex. Thirty-five giant ant specimens from the Eckfeld Maar were significantly differentiable from a collection of Messel specimens that consisted of 187 Titanomyrma gigantea females and $42 T$. gigantea males, and from 74 Titanomyrma simillima females and $21 T$. simillima males. Out of the 324 Messel ants, 127 are newly assigned to a species and 223 giant ants are newly assigned to sex with geometric morphometric analysis. All specimens from Messel fit to the two species. Moreover, shape affinities of these groups and the species Formicium brodiei, Formicium mirabile and Formicium berryi, which are known only from wings, were investigated. $T$. gigantea stands out with a possible female relative in one of the Eckfeld specimens whereas the other groups show similar shape patterns that are possibly plesiomorphic. Formicidae are one of the most dominant taxa in the animal kingdom and new methods can aid in investigating their diversity in the present and in deep time. Geometric morphometrics of the ant wing delivers significant results and 
this core of methods is able to enhance the toolset we have now to analyse the complex biology of the ants. It can prove as especially useful in the future when incorporated into better understanding aspects of evolutionary patterns and ant palaeontology. 
1 Giant ants and their shape: Revealing relationships in the genus

2 Titanomyrma with Geometric Morphometrics

3 Julian Katzke ${ }^{1}$, Phillip Barden ${ }^{2}$, Manuel Dehon ${ }^{3}$, Denis Michez ${ }^{3}$, Torsten Wappler ${ }^{1,4}$

$4{ }^{1}$ Steinmann Institut für Geologie, Mineralogie und Paläontologie, University of Bonn, Bonn,

5 Germany

$6{ }^{2}$ Department of Biological Sciences, New Jersey Institute of Technology, Newark, NJ, U.S.A.

$7 \quad{ }^{3}$ Laboratory of Zoology, Research Institute of Biosciences, University of Mons, Mons, Belgium

$8{ }^{4}$ Naturgeschichte, Hessisches Landesmuseum Darmstadt, Darmstadt, Germany

9 Corresponding Author:

10 Julian Katzke

11 Nussallee 8; Steinmann Institut; Abteilung Paläontologie, Bonn, North Rine-Westphalia, 53115,

12 Germany

13 Email address: jkatzke@uni-bonn.de 


\section{Abstract}

Shape is a natural phenomenon inherent to many different lifeforms. A modern technique to analyse shape is geometric morphometrics, which offers a whole range of methods concerning the pure shape of an object. The results from these methods have provided new insights into biological problems and have become especially useful in the fields of entomology and palaeontology. Despite the conspicuous successes in other hymenopteran groups, geometric morphometric analysis of wings and fossil wings of Formicidae has been neglected. Here we tested if landmarks defining the wing shape of fossil ants that belong to the genus Titanomyrma are reliable and if this technique is able to expose relationships among different groups of the largest Hymenoptera that ever lived. This study comprises 402 wings from 362 ants that were analysed and assigned with the geometric morphometric methods LDA, PCA, CVA, and regression. The giant ant genus Titanomyrma and the parataxon Formicium have different representatives that are all very similar but these modern methods were able to distinguish giant ant types even to the level of the sex. Thirty-five giant ant specimens from the Eckfeld Maar were significantly differentiable from a collection of Messel specimens that consisted of 187 Titanomyrma gigantea females and 42 T. gigantea males, and from 74 Titanomyrma simillima females and $21 \mathrm{~T}$. simillima males. Out of the $324 \mathrm{Messel}$ ants, 127 are newly assigned to a species and 223 giant ants are newly assigned to sex with geometric morphometric analysis. All specimens from Messel fit to the two species. Moreover, shape affinities of these groups and the species Formicium brodiei, Formicium mirabile and Formicium berryi, which are known only from wings, were investigated. $T$. gigantea stands out with a possible female relative in one of the Eckfeld specimens whereas the other groups show similar shape patterns that are possibly plesiomorphic. Formicidae are one of the most dominant taxa in the animal kingdom and new methods can aid in investigating their diversity in the present and in deep time. Geometric morphometrics of the ant wing delivers significant results and this core of methods is able to enhance the toolset we have now to analyse the complex biology of the ants. It can prove as especially useful in the future when incorporated into better understanding aspects of evolutionary patterns and ant palaeontology. 


\section{Introduction}

Geometric morphometrics (GM) is a recent core of methods aiming at quantifying and analysing the overall shape of a structure. By removing all non-shape variables (i.e. translation, rotation, and scale) and by separately analysing the size and the shape components of the form, the discrimination capabilities of GM are significantly superior to traditional morphometrics because they consider the shape as a whole rather than a collection of independent variables (Adams, Rohlf \& Slice, 2004; Slice, 2007; Zelditch, Swiderski \& Sheets, 2012; Klingenberg, 2016). The different techniques within the range of GM provide a powerful tool in anatomy, evolutionary biology, systematics, and palaeontology. One essential advantage of this technique is that it is applicable to most zoological taxa (both vertebrates and invertebrates) as well as to most botanical taxa (Viscosi \& Cardini, 2011; Bai et al., 2012; Maiorino et al., 2015; Lallensack, van Heteren \& Wings, 2016). For example, in bee systematics, morphology and morphometry of the wing usefully discriminate taxa at different levels: specimens, populations, subspecies, species, and tribes (Aytekin et al., 2007; Michez et al., 2009; De Meulemeester et al., 2012; Bonatti et al., 2014; Dehon et al., 2014, 2017). It has even been applied as an inexpensive alternative to molecular analysis to address genetic problems in bee tribes with morphologyderived results being similar to or more detailed than those obtained with mitochondrial DNA (Bonatti et al., 2014). As the method is rooted in morphology, it is especially interesting in palaeontology and palaeoecology where molecular approaches are inapplicable and taphonomy often destroys traditional morphological characters (Gunz et al., 2004; Wappler et al., 2012; Maiorino et al., 2013; Bonatti et al., 2014).

Ants are one of the most dominant groups in the terrestrial animal kingdom, both in diversity and biomass (Hölldobler \& Wilson, 1990). The origin of the Formicidae is estimated by molecular clock dating to lie within the Late Jurassic or Early Cretaceous (Brady et al., 2006; Moreau et al., 2006; Ward, 2007; Moreau \& Bell, 2013; Ward, 2014; Ward et al., 2015; Barden, 2017; Peters et al., 2017). The fossil record of the ants and close relatives starts in the Cretaceous with some early members of modern ant lineages but also an astonishing variety of specialized stem-Formicidae despite constituting only $\sim 1 \%$ or less of all insect fossils (Dlussky, 1999; Barden \& Grimaldi, 2013, 2014, 2016; Perrichot, Wang \& Engel, 2016). Ant diversity rose quickly in the Paleogene and by the Middle Eocene, most of the extant subfamilies are present in the fossil record (Grimaldi \& Agosti, 2000; Dlussky \& Rasnitsyn, 2002; LaPolla, Dlussky \& Perrichot, 2013; Ward, 2014). The abundance of the Formicidae in the fossil record steadily 
74 increases with ants making up to $13 \%$ of all insects in Eocene deposits, and over $24 \%$ in

75 younger Miocene deposits (Grimaldi \& Agosti, 2000; Dlussky \& Rasnitsyn, 2002; LaPolla,

76 Dlussky \& Perrichot, 2013).

One of the most remarkable formicid attributes is their eusocial behaviour. The scale of what is considered an ant colony ranges from merely around a dozen individuals in rainforests to the formicine ant Formica yessensis (W.M. Wheeler, 1913), which builds up polygynous "supercolonies" that comprise over 300 million adults and over 2.5 million queens alone (Wilson, 1959; Higashi \& Yamauchi, 1979; Hölldobler \& Wilson, 1990). Their origin and earliest evolution are still unresolved but formicid ecological dominance and abundance in fossil deposits quickly rose due to eusociality and the expansion of angiosperm forests (Moreau et al., 2006; Perrichot et al., 2007; LaPolla, Dlussky \& Perrichot, 2013; Rust \& Wappler, 2016; Barden, 2017).

Among ant castes, workers, which are much richer in individuals than queens or males, are primarily utilized to discuss biological problems. For Formicidae in general, the worker caste is extensively found in museum collections, they are often found in Cenozoic amber deposits, and they can be collected throughout the year in the field. However, only the queens and males possess wings, which are sometimes used in ant taxonomy to describe those castes (Yoshimura $\&$ Fisher, 2007, 2012). Although wings are acknowledged to be quite informative, especially in evolutionary relationships, they are neglected due to the workers' aptery and only few studies concern wing venation patterns (Brown \& Nutting, 1949; Perfilieva, 2000; Klingenberg \& Dietz, 2004; Perfilieva, 2010, 2015).

At the very core of this work stand the shape of the wing and the venational structures of the giant ants within the extinct formicoid subfamily Formiciinae. The Eocene giant ants are by far the largest known fossil or extant hymenopterans with up to $14 \mathrm{~cm}$ wing span and $7 \mathrm{~cm}$ body size but their position in the ant tree of life remains unclear (Lutz, 1986; Grimaldi, Agosti \& Carpenter, 1997; Archibald et al., 2011). Lutz (1986) put the Formiciinae as the sister group to the Formicinae due to form of the single petiolus and a reduced sting apparatus but phylogenetic reconstructions including giant ants by Baroni Urbani et al. (1992) and Grimaldi et al. (1997) placed the subfamily ambiguously due to much missing characters for the Eocene compression fossils. The Formiciinae currently comprise the genus Titanomyrma and the collective group Formicium, both with three species.

Here, the focus is set on the two described species Titanomyrma gigantea (H. Lutz, 1986) and Titanomyrma simillima (H. Lutz, 1986) from the Messel formation and on undetermined 
107 specimens from the Eckfeld Maar for whom affinities towards T. gigantea and T. simillima have

108 been stated, but no thorough description was provided (Wappler, 2003). The recent addition of a

109 single specimen of Titanomyrma lubei S.B. Archibald, 2011 from the Green River formation is

110 excluded from the analyses as unfortunately no wing venation is preserved (Archibald et al.,

111 2011).

112 Also included are single isolated wings of Formicium berryi (F.M. Carpenter, 1929) and

113 Formicium brodiei J.O. Westwood, 1854 from the Claiborne and Bracklesham Groups,

114 respectively (Westwood, 1854; Carpenter, 1929). The last species in the Formiciinae is

115 Formicium mirabile (T.D. Cockerell, 1920), which was originally thought to be a sawfly and is,

116 like F. brodiei, from the Bracklesham Group (Cockerell, 1920; Lutz, 1990).

117 The Formiciinae are found exclusively from the latest Ypresian (early Eocene) to the

118 Lutetian (early middle Eocene) of Central Europe (Bracklesham Group, England and Messel and

119 Eckfeld, Germany) and mid-continental North America (Green River Beds, Wyoming and the

120 Claiborne Group, Tennessee). The ages of the oil shales from Eckfeld and Messel are now well

121 established by means of numerical dating: Messel lake is $48.7 \pm 0.2 \mathrm{Ma}$ old with a duration of

122 about $640 \mathrm{Ka}$ (Mertz \& Renne, 2005) and the Eckfeld maar eruption has an age of $44.3 \pm 0.4 \mathrm{Ma}$

123 (Mertz et al., 2000; Lutz et al., 2010).

124 Until recently, each giant Eocene ant was attributed to the genus Formicium. For the

125 species from Messel, T. gigantea and T. simillima, the genus "Formicium" as described by Lutz

126 (1986) is no longer valid because Formicium has since been defined as a parataxon that collects

127 species described from wings only (Archibald et al., 2011). Titanomyrma now serves as the

128 orthotaxon for species described from complete or rather complete bodies, most with wings

129 preserved. When described in the future, Eckfeld specimens will also be attributed to

130 Titanomyrma. However, it has to be stated that the revision by Archibald et al. (2011) still leaves

131 nomenclatural problems. The species T. gigantea and T. simillima have been used with the neuter

132 suffix -um. Here and in other appearances, the proper feminine suffix is used. The subfamily

133 Formiciinae also becomes problematic with the treatment of Formicium as a parataxon because

134 the subfamily is now represented by a parataxon as its type species where it should refer to the

135 orthotaxon. Either a new subfamily name is needed or, with more information provided by new

136 studies, giant ants can be incorporated into an existing subfamily. When speaking collectively of

137 the giant ants, the terms Formiciinae and Titanomyrma are used. Formicium is only used when

138 exclusively addressing the wing species. 
To investigate if the ant wing is a strong taxonomic character, modern techniques need to

140 be applied to evaluate wing venation as a window into evolutionary pathways and species-level

141 diversity. Geometric morphometrics of the hymenopteran wing in general is a thriving method to

142 analyse and discuss morphological issues within and across taxa, both in extant and fossil

143 lineages (Michez et al., 2009; Francoy et al., 2011; Wappler et al., 2012; Bonatti et al., 2014;

144 Dehon et al., 2014; Perrard, Lopez-Osorio \& Carpenter, 2016; Dehon et al., 2017). However,

$145 \mathrm{GM}$ is frequently unused in the Formicidae aside from investigations on cryptic diversity using

146 the ant-body (Csosz et al., 2014; Seifert, Yazdi \& Schultz, 2014). The aims of this work are to

147 validate the wing venation of the Formiciinae as a statistically robust set of characters and to

148 distinguish different groups of formiciine ants from the level of species up to the distinction of

149 sex with GM. The data from Messel is expected to show a clear division into the species $T$.

150 gigantea and T. simillima and undetermined specimens should be assignable to either these

151 species or cluster within a new group. Wing venation for males and females of T. gigantea should

152 differ from representatives of T. simillima, with at least the four described morphogroups that are

153 distinguishable in analyses. These morphogroups are expected to reflect currently defined species

154 diagnoses sensu Lutz (1986). Ants from Eckfeld, which are formerly uncategorized, as well as $F$.

155 brodiei, F. mirabile, and F. berryi are expected to show affinities to other giant ants and those

156 affinities will be described and discussed thoroughly.

\section{Material \& Methods}

158

\section{Sampling of specimens}

Included in this work are wings of a greater collection of fossils belonging to the giant-ant genus Titanomyrma. The detailed analysis of Titanomyrma specimens from Messel and Eckfeld was performed using 399 wings with the addition of wing drawings of the holotypes of Formicium brodiei and Formicium berryi provided by Lutz (1986) and Formicium mirabile provided by Lutz (1990). Due to 40 specimens having both forewings preserved, this study represents 362 ants. A detailed list of specimens with both wings preserved can be found in the supplementary tables Tables S1 \& S2. The fossils used are taken from the collections of the Hessian State Museum (HLMD), Natural History Museum Mainz (PE= Paleogene Eckfeld, LS= State Collection), and Senckenberg Research Institute and Natural History Museum (MeI= 
168 Messel Inventory). Photographs had been taken by Uta Kiel, Sonja Wedmann, and Torsten

169 Wappler and were used as the foundation for assessing landmarks.

170 Assignments of Titanomyrma ants were done by Lutz (1986) and some were provided by

171 Wappler (pers. comm.) based on wing venation characters and measurements and calculations of

172 the crowding factor sensu Lutz (1986). These specimens were re-evaluated in the geometric

173 morphometric analysis in combination with Lutz's (1986) diagnosis of the species (Table S3). A

174 list of the specimens with prior assignment is found in Tables S1 \& S3.

175 For the Messel fossils, 240 out of the 358 wings (219 out of 324 specimens) had been

176 previously assigned to a respective species sensu Lutz (1986). T. gigantea was represented with

177180 wings (164 ants) and T. simillima with 60 wings (55 specimens). Only 125 Messel wings had

178 been assigned to either female or male (114 specimens). Females were represented with 109

179 wings (100 specimens), males are represented with 16 wings (14 specimens).

180 In a more detailed view, prior to this study, a total of 117 Titanomyrma wings (106

181 specimens) from Messel had already been assigned to both species and sex. A separation

182 following the classifiers sex and species yielded a total of 87 determined female $T$. gigantea

183 wings ( 80 specimens), 17 determined female $T$. simillima wings (15 specimens), 6 determined

184 male $T$. gigantea wings (5 specimens), and 7 determined male $T$. simillima wings (6 specimens).

185 Specimens from Eckfeld had no prior species assignment, out of the 41 wings (35 specimens), 13

186 (11 specimens) were assigned as male wings and 1 wing (1 specimen) was assigned to female.

\section{Wing venation and landmark definition}

Nomenclature for the wing venation of ants was established by Brown \& Nutting (1949)

189 for Formicidae following Ross's work (1936) that tried to homologise hymenopteran wing venation and erected the terminology. The wing venation terminology used here primarily follows these works with the following modifications: Consecutive numbering is only used for

192 the median and radial-sector veins, the branches of the cubitus are labelled Cua and Cub, radio-

193 medial cross-vein $r-m$ becomes $r s-m$ as it connects the radial sector with the median.

Titanomyrma has a very basic set of veins and almost all wing cells that would occur in a

195 basal representative of the Formicidae are present (Fig. 1A). The only modification to the basal

196 condition in Titanomyrma is the absence of the first radial cross-vein $1 r$. That vein is also reduced

197 in other ants of the formicoid clade except for some of the Dorylinae, for example Cheliomyrmex

198 (Brown \& Nutting, 1949; Bolton, 2016). The position of $m$-cu in Titanomyrma is highly variable 
199 in front or behind the branching of the radial-sector vein. This makes the classical nomenclature 200 of the median veins more difficult as $m$-cu separates $M 2$ and $M 3$. If a coherent homologisation is

201 desired, it is suggested to use the term $R s+M$ for any part where the radial-sector and median vein 202 is fused so in different Titanomyrma species the median vein M2 may or may not be reduced.

203 Many compression fossils lack a proper preservation of the wing margins, which is why

204 only the central wing cells $1-2 \mathrm{R}, 1 \mathrm{Rs}$, and $1 \mathrm{M}$ and vein $c u-a$ have been considered for landmark

205 assignment. For each fossil of the Titanomyrma species, 12 landmarks were identified and placed

206 (Fig. 1B). LM1, 2, 3, 4, 7, and 9 surround the radial cells $1 \mathrm{R}$ and 2R, which are fused in

207 Titanomyrma to $1-2 \mathrm{R}$ due to the reduction of the first radial cross-vein $1 r$. LM4, 5, 6, 7, and 8

208 define the shape of the first radial-sector cell 1Rs. LM8 co-defines the shape of 1Rs as it marks

209 the separation between vein M2 and M3. However, due to the variable position of $m-c u$, LM8

210 may be excluded from this observation. The first medial cell $1 \mathrm{M}$ is surrounded by LM8, 9, 10,

211 and 12. The position of $c u-a$ is defined by LM11.

212

213

214

215

216

217

218

219

220

221

222

223

224

225

226

227

228

229

\section{Data preparation}

Landmarks were digitalised by J. Katzke onto the wing pictures using tpsDig2, version 2.28 (Rohlf, 2016a, Data S1-2) and analysed using MorphoJ, version 1.06 (Klingenberg, 2011, Data S3-4). To make all available specimens comparable using GM, all images have to resemble a dorsal view of the right forewing, which is practical for wings as they are almost twodimensional structures. Wings and imprints appearing right-handed did not have to be altered whereas wings and imprints appearing left-handed were converted by mirroring them on the vertical axis.

Although the Titanomyrma fossils are expected to differ significantly in shape, they also differ greatly in size. T. gigantea and T. simillima females are described to be the real giants with the length of a single forewing measuring 4-6 cm (Lutz, 1986). Male wings are significantly smaller with 2-3 cm (Lutz, 1986). A way to include the size of a specimen along with the shape information is the clear definition of the "centroid size" in a set of landmarks and to make that available for further analyses (Klingenberg, 2011; Zelditch, Swiderski \& Sheets, 2012). In this case, a total of 331 wings provided information that could be used to include scaling. A list of these specimens is found in Tables S1 \& S2.

To compare the Formiciinae with each other and to assign species to previously unidentified specimens, different classifiers were created using prior identifications and 
230 descriptions of the fossils. The specimens are grouped by: locality: Messel, Eckfeld, England, or

231 Tennessee; species: T. giganteum, T. simillima, F. brodiei, F. berryi, or T. sp.; sex: male, female, 232 or undetermined.

\section{Estimating missing data using $\mathbf{R}$}

Out of the 402 wings, 80 have missing landmarks, which would exclude them from any further morphometric analysis because applications for data analysis always require the full set of landmarks to calculate the shape differences. Both MorphoJ and programs in " $\mathrm{R}$ " are unable to ignore missing landmarks because the analyses focus on the shape as a whole. In palaeontological datasets, missing data is a commonly encountered problem and several computational methods have been made available and applied successfully over the last 13 years (Gunz et al., 2004; Maiorino et al., 2013, 2015; Hopkins \& Pearson, 2016). A list of specimens with missing data can be found in Tables S1 \& S2 and the missing landmarks themselves are listed in Data S1.

Missing landmarks were estimated using R, version 3.3.1 (R Core Team, 2016) package "Morpho", version 2.5.1 with the command "fixLMtps" (Schlager, 2017). The command uses thin-plate-spline-interpolation techniques according to the inverted Procrustes distances between landmark observations of, in this case five, most similarly shaped individuals (Schlager, 2017). the specimens instead of the "ID="-lines (Data S5).

Three wings from Eckfeld and 77 wings from Messel that are included in the dataset have missing landmarks. The estimations for the Eckfeld specimens were performed separately from the Messel specimens and subsequently the files were appended again using tpsUtil, version 1.74 of other species in the genus Titanomyrma if there was not enough shape difference between species or if there were multiple undiscovered species. The estimated landmarks are collected with the manually placed ones as the final dataset in Data S2.

\section{Data Analysis}

Before performing different analyses, the curved shape space, which is defined by the raw data, was transformed into the Euclidean distances tangent space via full Procrustes superimposition, which is the crucial step in geometric morphometric analysis (Kendall, 1977; 
261 (Rohlf, 1999). It is theoretically possible that the variation in the dataset is too large for the

262 tangent space being approximate to the curved shape space. By calculating the regression slope

263 and the correlation coefficient between the Procrustes distances in the shape space and the

264 Euclidean distances in the tangent space, it is possible to ascertain whether or not the variation

265 amplitude in the dataset is small enough to perform further analyses (Rohlf, 2015). This analysis

266 was performed with the software tpsSmall, version 1.33 (Rohlf, 2016b).

The dataset yielded from Data S2 was divided into subdatasets (SDs 1-12) in MorphoJ by

268 implementing different classifier information (Tables S1 \& S2). The 80 wings from specimens

269 with both wings preserved were treated as individuals in most of the analyses. In order to validate

270 this treatment, variation in a subsample of $17 \mathrm{~T}$. gigantea previously determined females with

271 preservation of both forewings was analysed (SDs $1 \&$ 2, Data S3, Table S1). For a shape-related

272 analysis of the species T. gigantea and T. simillima, Messel specimens were collected in SDs 3-8

273 (Data S4). Questions concerning assignment of species and sex with geometric morphometrics

274 and sexual dimorphism were investigated. Shape affinities and size of Titanomyrma groups were

275 analyzed using SDs 9-12 (Data S4).

276 Different methods of GM were applied to the subdatasets to gain insights into the

277 relationships between giant ants and to test existing classifications (Tab. 1). The methods applied

278 here are well established in works using GM to analyse wing venation patterns and wing shape in

279 Hymenoptera (Perfilieva, 2010; Bonatti et al., 2014; Dehon et al., 2014, 2017).

\section{Principal Component Analysis and Canonical Variate Analysis}

Principal Component Analysis (PCA) was widely used in this work to visualize and

investigate variation in the dataset. A PCA transforms the total possible observations and reduces them to a data dependent number of "principal components" (PCs) that explain the total variation within a dataset (Zelditch, Swiderski \& Sheets, 2012). In contrast to principal component analysis, the canonical variate analysis or CVA calculates and visualizes the differences between a priori groups (Klingenberg, 2011; Zelditch, Swiderski \& Sheets, 2012). PCA visualizes variation in the dataset and CVA visualizes differences between groups (Zelditch, Swiderski \& Sheets, 2012).

\section{Linear Discriminant Function Analysis}

The Linear Discriminant Function Analysis (LDA) is a method of multivariate analysis of variance. LDA uses the mean shapes of a priori defined groups to make an assertion of the significance of the groups (Klingenberg, 2011). The LDAs were performed using a cross-

292 validation approach within MorphoJ (SDs 2, 6, 9, \& 12) and results were collected within Table 
Each separable group, assumed after classifier criteria, was tested against the other groups

295

296

297

298

299

300

301

302

303

304

305

306

307

308

309

310

311

312

313

314

315

316

317

318

319

320

321

322

323

to estimate shape related associations among the groups. Eckfeld specimens were tested as their own group. The effectiveness of the cross-validation assignment of the groups is measured by the hit-ratio (HR) of how many specimens could be reassigned to their original group.

\section{Regression modelling to investigate size-related effects}

To test whether there is a significant influence of size on shape that can distort the differentiation of species, sex, or both in combination, statistical regression can be applied in MorphoJ to analyse effects of allometry, the relation between size and morphology (Klingenberg, 2011). The aim of the regression is to analyse relationships between dependent and independent variables within a dataset. In this case, shape is the dependent variable linked to the Euclidean distances gained from Procrustes superimposition. Centroid size is at least theoretically independent from shape but shape can be predicted for any centroid size if there is allometry (Klingenberg, 2011). A residual shape, which is the deviation from the prediction, remains. The residual part in shape does not covary with the centroid size or actual size (Klingenberg, 2011). When differentiable groups are present within the dataset, it is possible to perform a pooledwithin-group regression to see whether or not their different sizes are affecting the shape differences among the groups (Klingenberg, 2016). This was done with SD 6, 10, and 12 to investigate sexual dimorphism in Titanomyrma. The regression as a method to test size influence in a dataset is only advisable if there actually is an association between increasing size and shape change (Zelditch, Swiderski \& Sheets, 2012; Klingenberg, 2016).

\section{Results}

Using the Procrustes fitted data in the analysis is possible as the Euclidean distances in tangent space approximate the Procrustes distances in shape space for a total of 402 Titanomyrma/Formicium wings. This is indicated by the regression slope being very close to 1 (0.9967) and an equally high correlation coefficient of 0.9999.

\section{Variation within single specimens}

At first, the smaller subsample of 17 determined T. gigantea female ants was analysed, of which all 17 show both wings preserved (SD 1). In a PCA, PCs1-6 describe more than $5 \%$ variance each and PCs1-3 describe more than $10 \%$ variance each. The main variation does not represent a separation in left and right wings. It also does not depict single ants being severely 
324 different from the others. The highest variation described by PC1 (31.25\%) comes from the 325 relative size of wing cell 1 Rs. The 17 T. gigantea females show a very homogenous shape as 326 indicated by the shape changes of the PCs. In the PCs, there is no separation of distinctive wing 327 pairs at all. A clear separation of a single ant, MeI409, is the result of a CVA of the subsample 328 grouped after specimen $(\mathrm{CV} 1=86.99 \%)$. The CVA results in $16 \mathrm{CVs}$ (17 groups) that are able to 329 differentiate the groups but with $87 \%$ of the results being insignificant $(p>0.05)$. A separation of 330 left and right wings in a CVA is not possible. Using the LDA in SD 2, the permutation tests result 331 in insignificant values with only one significant result $(p<0.05)$. The allocation of wing pairs to 332 each other in a cross-validation approach is unsuccessful throughout tests regarding each wing 333 pair against other ant wings.

334 The independence of shape between left and right wings of single specimens creates a 335 confining factor for GM as a quantitative method. It is not possible to assign an isolated

336 Titanomyrma wing to its counterpart. Cutting the specimens that are isolated wings in half would

337 be a means to estimate the least amount of ants that are preserved. However, during

338 biostratinomy a once connected pair of fragile ant wings is influenced by several confounding

339 factors such as predators, currents, or different sinking speeds. From a taphonomical point of 340 view, it is highly doubtful that any of the isolated wings preserved has a matching counterpart in 341 the same dataset.

\section{Shape discrimination between Messel species}

The described species with specimens predetermined as Titanomyrma gigantea and

Titanomyrma simillima are clearly separable by comparing their wing shape in a PCA (SD 3, Fig. 2A). Moreover, all undetermined specimens from Messel cluster within the group of either $T$. gigantea or T. simillima (Fig. 2A). Out of the predetermined specimens, nine were reassigned to the other species (Table S3). Wing shape of the undetermined specimens can easily assign them to the two species as they cluster within the range of either T. gigantea or T. simillima. PCs1-3 each explain more than $5 \%$ of the total variance in the dataset. PC1 represents $58.31 \%$ variance and PC2 represents $13.60 \%$ variance, and they both describe clear shape trends in

352 distinguishable groups. There is a separation of larger and smaller specimens in PC2 (Fig. 2B).

353 The two species T. gigantea and T. simillima are separated in PC1, which describes differences in 354 shape that are clearly observable in the mean shapes of the two species (Fig. 2A). The most 
355 important vein for the distinction between the species is $m-c u$, which is virtually in line with $R s 1$

356 in T. gigantea similar to Camponotus ants. A small distance of $m$-cu occurs in some individuals,

357 especially smaller specimens. Another difference is the position of $c u-a$, the connection between

358 the cubital and anal veins that is also used as a delimitating factor in other ant groups (Brown \&

359 Nutting, 1949; Perfilieva, 2010, 2015). In T. simillima, cu-a is somewhat more variable and

360 nearer towards the ant-body than in T. gigantea where most often $c u$ - $a$ and $M 1$ build up a

361 junction with $M+C u$ and $C u$. The vein $r s-m$, which connects the radial-sector and the median

362 veins is well expressed in T. simillima and reduced in T. gigantea so that those veins are directly

363 in contact and appear in coalescence. In general, $T$. gigantea is denser in its wing venation than $T$.

364 simillima, which corresponds to the higher crowding calculated by Lutz (1986).

365 MeI4060 is the only intermediate specimen in a PCA (Fig. 2A). The wing is well

366 preserved but shows white patches in all the critical veins, which made the digitalisation of

367 landmarks more difficult. An offset of the veins $R s 1$ and $m$-cu puts the individual into the species

368 T. simillima and additionally, $c u-a$ is also a bit distant from $M 1$.

369 As no third larger group was detected in the Messel specimens, out of 127 undetermined

370 wings, 81 were assigned to T. gigantea $(\mathrm{n}=257)$ and 46 to T. simillima $(\mathrm{n}=101)$, which is

371 statistically robust using the LDA in SD 9 with hit ratios (HRs) of $100 \%$ and significant $p$ -

372 values $(<0.0001)$ in both Procrustes and Mahalanobis distances (Table S4).

373 Shape discrimination between sex in Messel specimens

374 There is sexual size and shape dimorphism in Titanomyrma related to PC2 of the Messel

375 PCA (Fig. 2B, SD 3). The shape difference may be attributed to allometry and the size difference

376 of females and males. For the sexual assignment of the undetermined specimens, when present,

377 size information was used after species determination. Otherwise, PCA for each species could be

378 applied to assign the specimens to either male or female (SDs 4 \& 5). Out of the predetermined

379 specimens, two were attributed to the wrong sex (Table S3). Assignment to sex provides 64 new

380 T. simillima females, 16 new T. simillima males, 123 new T. gigantea females, and 37 new $T$.

381 gigantea males. Regression pooled within both species suggests a linear combination of shape

382 and size and that size difference predicts shape (SD 6). This regression results in $20.54 \%$

383 predicted values and the sex difference is almost entirely contained in the prediction. The

384 residuals leave no sexual shape variation, only that of the species. The shape change, which is

385 realised in increasing centroid size, resembles the shape change in PC2 from the PCA of

386 Titanomyrma specimens from Messel (Fig. 2B, SD 3). LDA regarding sex on the regression

387 residuals is grossly insignificant $(p=0.79)$ whereas LDA on the prediction assigns $100 \%$ of the 
388 males correctly and $84.44 \%$ of the females ( $p<0.0001$, SD 6Table S4). In Messel, Titanomyrma

389 males and females differ in their relative wing width, which affects both species and the males

390 are always much smaller than the females. The shape of the wing venation of the males is

391 generally congruent with the typical condition for the respective females (see Fig. 2A). That $T$.

392 simillima and T. gigantea share the same pattern of shape dimorphism despite being differentiable

393 in shape, speaks for a size-related allometric origin of that dimorphism.

394 However, besides the female wings being narrower, there are also other slight shape

395 differences in the sexes for each species that make them distinguishable using GM. In general,

396 the differences between T. simillima males and females are more numerous and easier to observe

397 than the ones between $T$. gigantea representatives. The alignment of $m-c u$ and $R s 1$ is not as

398 progressed in T. gigantea males as in the females (Fig. 3A). In T. simillima, M2 is relatively

399 larger in males as well as $r s-m$. Moreover, the positioning of $c u-a$ is generally more proximal to

400 the wing base in male specimens of T. simillima (Fig. 3B). Despite a trend of narrower female

401 wings, results of PCA after assignment to sex are diffuse for the individual species; in T. gigantea

402 (SD 7), no relation of PCs offers a clear distinction between sexes whereas a distinction in $T$.

403 simillima (SD 8) is still possible (Fig. 3C, 3D). Strong outliers in these analyses are included in

404 Table S3.

$405 \quad$ Following species assignment, the linear discriminant function analysis improves upon

406 sex discrimination relative to shape affinities revealed by principal components. In the cross-

407 validation approach of the LDA, the specimens are significantly well separable (SD 9, Table S4).

408 T. simillima females show a 98.25\% HR (n=80) and T. simillima males show a $100 \% \mathrm{HR}$

409 (n=21). T. gigantea females show a $99.03 \mathrm{HR}(\mathrm{n}=207)$ and T. gigantea males show a $98 \% \mathrm{HR}$

$410(n=50)$. These results suggest that there is in fact solid shape discrimination between males and

411 females of both species and that sexual dimorphism in Titanomyrma affects both size and shape.

\section{Shape trends of all specimens and assignment of Eckfeld specimens}

In a second approach performing a PCA on all Titanomyrma specimens available (SD 9),

414 T. gigantea from Messel clusters on one side of the plot and all the other specimens gather on the 415 other side in PC1 (Fig. 4A). One exception constitutes PE_1994_167-LS, which appears within

416 the range of T. gigantea. PE_1994_167-LS has the typical crossing of Rs 1 and $m$-cu with the

417 median vein, which is never observable in T. simillima or the other Eckfeld specimens. The

418 unambiguous distinction of $T$. gigantea from the other groups is also supported by the LDA,

419 which results in $100 \%$ HRs $(p<0.0001$, SD 9Table S4). All the Titanomyrma groups are 
420 separable using a combination of shape variables and size (SD 10, Fig. 4B). T. simillima males

421 are the smallest wings with about $23 \mathrm{~mm}$ (Lutz, 1986). Most of the Eckfeld specimens have

422 roughly the same size as T. gigantea males with about $27 \mathrm{~mm}$ but they differ in shape (Lutz,

423 1986). F. brodei and F. berryi also exhibit a wing length of about 26-27 mm (Lutz, 1986). Female

424 wings of the species $T$. gigantea measure about $60 \mathrm{~mm}$, whereas female $T$. simillima wing only

425 measure about $45 \mathrm{~mm}$ (Lutz, 1986). F. mirabile is closer in size to T. gigantea females with about

$42654 \mathrm{~mm}$ but closer in shape towards T. simillima (Fig. 4A, Lutz, 1990). Two specimens from

427 Eckfeld, PE_1994_167-LS and PE_1998_17-LS are much larger than the rest of the Eckfeld

428 specimens and are interpreted as females. In size and shape, PE_1994_167-LS is well within the

429 range of T. gigantea females. PE_1998_17-LS is just above the size of T. simillima females and is

430 close in shape. The other 37 Eckfeld wings were all classified as males because they are similar

431 in size and shape. Five Eckfeld specimens fall in the range of small T. simillima females but are

432 nevertheless assigned as males: PE-1990-582-LS, PE-1992-258-LS, PE-1992-506-LS, PE-2000-

433 15-LS, and PE-2000-18-LS. This could be a misinterpretation but as seen in Messel, the size

434 differences between males and females are drastic, more drastic than it would be in these five

435 specimens. Moreover, no further shape discrimination is detectable between these five larger

436 specimens and the others (Fig. 4A and see Figure S1, SD 12). The overall determination as

437 Eckfeld males is confidently undertaken not only because of their size ranging within that of $T$.

438 gigantea males, but also because of specimen PE_2000_3-LS, of which Wappler (2003)

439 thoroughly described a male genital apparatus.

440 LDA is not applicable to groups with only one specimen, which concerns F. brodiei, F.

441 berryi, F. mirabile, and the larger Eckfeld specimens. For all discriminable groups that have more

442 than one specimen (T. gigantea females; $\mathrm{n}=207$, T. gigantea males; $\mathrm{n}=50, T$. simillima females;

$443 \mathrm{n}=80$, T. simillima males; $\mathrm{n}=21$, Eckfeld males; $\mathrm{n}=39$ ), the results of the LDA show combined

444 HRs of more than $97 \%$ for each group against the others with significant $p$-values (SD 9, Table

445 S4). In a PCA, the largest specimens cluster with the rest of T. sp. from Eckfeld and F. brodiei in

446 PC2 (Fig. 4A). The shape change realised in PC2 is the same as in Fig. 2B so Eckfeld males have

447 narrower wings than males from Messel and no Eckfeld female wing is explicitly narrower (Fig.

448 4A). Thus, narrow wings are not necessarily a Titanomyrma trait for the larger females. The five

449 larger Eckfeld males are also scattered across the cluster (Fig. 4A). In a PCA concerning only

450 Eckfeld specimens, Eckfeld females cluster on opposite sides in PC1 with only $20.85 \%$

451 variation, leaving the males slightly intermediate (Figure S1, SD 12). Apart from that and size, no

452 sexual shape dimorphism is evident in Eckfeld. 
An attempt for size-correction by pooled within group-regression slightly alters the shape

454 trends in Titanomyrma specimens from Messel and Eckfeld (SD 10, Fig. 4C). Eckfeld specimens, 455 which are roughly the same size as $T$. gigantea males or smaller $F$. simillima females cluster with 456 other males in PC2 after size correction (Fig.4C). Most shape variation, represented by PC1 in 457 the PCA, separates T. gigantea from any other group of giant ants. This is independent from size, 458 before allometric correction, PC1 has loadings of 58.44 \% and after size correction PC1 contains $60.65 \%$ of the total variation. Results of the LDA are improved after size correction in the groups that are tested. The HRs are higher with $98.71 \%$ and all $p$-values show strong significance $(<0.0001)$. The realised shape change for the males however, is ambiguous: relatively smaller wing cells and a greater distance between $c u-a$ and $M 1$. After the attempt for size correction, there seems to be a separation of male and female Titanomyrma specimens, but these analyses are based on altered data and they do not represent the natural shape of the wings.

Ten different groups of Titanomyrma ants are presented in this study. However, five are only represented with single specimens (Fig. 5). For T. gigantea females and males, for $T$. simillima females and males, and for $T$. sp. males from Eckfeld, the similarity of many wings has been quantified by geometric morphometric analyses. Different aspects of the wing venation and the shape of wing cells $1-2 \mathrm{R}, 1 \mathrm{Rs}$, and $1 \mathrm{M}$ characterise the five larger groups and the five single specimens (Tab. 2). Especially T. gigantea is distinct by two crossings of veins: $1 . M+C u, C u$, $M 1, m-c u$, and 2. M1, M3, Rs 1, $m-c u$. The reduction of $r s-m$ however, is observable both in $T$. gigantea and $T$. sp. but in T. gigantea females it is most advanced. A more generalized pattern of wing venation is observable in giant ants that do not belong to T. gigantea.

\section{Affinities among Titanomyrma simillima and Eckfeld specimens}

476 (except for PE_1994_167-LS) than there are with T. gigantea. The main variance that is explained by principal components in all present Titanomyrma groups is always the difference between T. gigantea and others. The similarities and differences in this "simillima-morphogroup" (comprising all non-T. gigantea specimens) have to be investigated without $T$. gigantea affecting the total variation. Separating the simillima-morphogroup (SD 11) from the T. gigantea-data, reveals a clearer pattern in a PCA (Fig. 6). Eckfeld specimens were determined as males according to Wappler's (2003) identification of male genitalia but males of T. simillima are clearly separated from the bulk in PC1, which represents the greatest variation in the dataset but with only $26.55 \%$ variation. The negative loadings of PC1 that separate males of T. simillima are 
$486 a$ and $M 1$ (Fig. 6B). By comparing the mean shapes of the Eckfeld specimens and T. simillima

487 males, the same shape differences are evident (Fig. 6C). However, except for relative size, wing

488 cells $1-2 \mathrm{R}$ and $1 \mathrm{M}$ are similarly shaped. Aside from the relative length of $r s-m$, cell 1 Rs is very

489 similar in the angle between $R s 2-3$ and $R s 4$ and the relative length of these veins and $M 2$, which

490 is almost always unrecognisable in other Titanomyrma groups. The cross-validation approach of

491 the LDA separates T. simillima from Eckfeld males with a $100 \% \mathrm{HR}(p<0.0001)$. The distinction

492 of the Eckfeld males from T. simillima males is supported by the LDA with $94.87 \% \mathrm{HR}$

$493(p<0.0001$, SD 9, Table S4). However, this is the lowest individual HR in the LDA among all the 494 groups tested.

495 Principal component analyses reveal that $T$. $s p$. and T. simillima females share almost the

496 same shape patterns and that there is little variation between them (Fig. 4A \& 6A). Still, in

497 comparison to female T. simillima, males from Eckfeld have a less crowded cell 1Rs, the veins

$498 R s+M$ and $M 2$ are short but developed, and intriguingly, vein $r s-m$ is shortened (Fig. 6D). This

499 reduction of $r s-m$ and the size of the Eckfeld males are shared with T. gigantea whereas the

500 general shape pattern is close to T. simillima. The LDA is able to separate Eckfeld males from $T$.

501 simillima females with 97.44 \% HR and T. simillima females from Eckfeld males with 96.25 \%

502 HR. In a CVA of the simillima-morphogroup, CV2 (41.36\%) collects T. simillima females and

503 Eckfeld males but discriminates T. simillima and T. sp. from Eckfeld (including PE_1998_17-LS)

504 in the positive and negative values (Fig. 6E \& 6F). The CV1 shape change is almost identical to

505 the comparison of T. simillima females and Eckfeld males, which is probably due to the higher

506 numbers of individuals. Nevertheless, this represents a difference between T. simillima and the

507 Eckfeld specimens.

508 Summarized, T. $s p$. from Eckfeld has a reduced $r s-m$ in the pattern of T. gigantea and M2

509 is well identifiable in contrast to T. simillima. The relatively narrow wings and the similarity in

510 shape to the single female specimen PE_1998_17-LS leave a sexual shape dimorphism as clearly

511 seen in Messel questionable for T. sp. from Eckfeld. In general, the wing shape is more

512 generalized as it is in T. simillima, F. brodiei, and F. mirabile although the groups are evidently

513 separated from each other in terms of age and locality. Intriguingly, F. brodiei has the same size

514 as the Eckfeld males and F. mirabile has approximately the same size as PE_1998_17-LS. 


\section{Distribution of giant ants within Localities}

516

517

518

519

520

521

522

523

524

525

526

527

528

529

530

531

532

533

534

535

536

537

538

539

540

541

542

543

All specimens are assigned to species and sex with the Eckfeld specimens being mostly males of probably the same species with two exceptions. Specimens with two wings preserved are represented two times each in the dataset and have to be halved for an individual-level count. Undetermined specimens from Messel are assigned with PCA (SD 3); their sex is determined by size and PCA (SDs 4-8). PE_1994_167-LS from Eckfeld shows affinities towards T. gigantea and its size is suggestive of a female wing (SDs 9 \& 10). PE_1998_17-LS is assigned as a female that shows affinities towards T. simillima and is more similar to the 33 males that constitute the rest of the Eckfeld dataset (SDs 9-12). Fig. 7 shows a list and a pie chart of the distribution of specimens in the dataset. The ratio of males is about $20 \%$ males in Messel. In Eckfeld, the specimens consist of 80-94\% males, depending on whether or not the five specimens that have the size of smaller T. simillima females are interpreted as Eckfeld females. In Messel, $29 \%$ of all Titanomyrma ants belong to the species T. simillima. Lutz (1986) concluded a similar ratio in Messel but the proportion of T. simillima as a species has decreased with more specimens assigned.

\section{Discussion}

\section{Landmarks for ants and ant fossils}

Using a system of 12 landmarks in a formicid with a generalised condition in its wing venation bears several advantages especially looking at different qualities of preservation in the fossil record. Nevertheless, regarding the evolutionary development of different ant taxa, for a general set of landmarks, other configurations of landmarks are possible. In a generalized ant wing dataset where all critical points in the venation are considered, a set of $23+2$ landmarks is possible (Fig. 8). The other 11 landmarks, in addition to the 12 landmarks used here, mostly relate to origins and apices of the horizontal veins to encompass the wing shape as a whole in contrast to using only three wing cells and $c u$ - $a$. Additional landmarks for the complete description of the most ancestral ant wing would include two landmarks for the anterior and posterior ends of $1 r$, a vein most often reduced but still present even in extant Formicidae like the South American army ant Cheliomyrmex morosus (F. Smith, 1859) or sometimes found as atavisms in other taxa (Brown \& Nutting, 1949). Cross vein $1 r$ as an atavism extends to 
544 Titanomyrma as seen in the holotype of $F$. mirabile and the female $T$. gigantea specimen

545 MeI14311.

$546 \quad$ Alternative numbers for analysed landmarks are as sparse as publications on ant wing

547 GM. Perfilieva (2010) used a set of 13 landmarks for a study including all major ant subfamilies,

548 and Perfilieva (2015) used a set of 16 landmarks for a study concerning Myrmeciinae and

549 Ponerinae. The lower number in the former publication is due to the fact that many ant lineages

550 reduced cell 1Rs so landmarks concerning this cell are often not placeable. It should be noted that

551 it is not possible to include landmark loss, and corresponding cell loss, into morphometric

552 analysis. The additions in shape assessment compared to our study encompass the overall length

553 of the wing and cell $1 \mathrm{Cu}$, which is shaped by veins $C u, A$, and $c u$ - $a$. Including the overall length

554 of the ant wing by using the apex and the base of the wing for landmarks is helpful in visualizing

555 relative sizes of the wing cells. These landmarks make crowding more visible. However, the

556 higher crowding for T. gigantea estimated by Lutz (1986) is also represented in our study by PC1

557 in PCAs that include T. gigantea amongst other groups. Additional landmarks are not necessary

558 to assess the relative sizes of wing cells when they are compared with other groups.

559 The shape of the cubital wing cell $1 \mathrm{Cu}$ is not discriminated in this study. A separation

560 between Ponerinae and formicoid ants could be observed by the shape of 1Cu (Perfilieva, 2010).

561 Further including this cell could give interesting insights in general shape trends of the ant wing

562 venation as this cell is highly variable among ant taxa and especially the position of $c u-a$ is

563 notoriously variable even in left and right wings of a single ant (Brown \& Nutting, 1949;

564 Wappler, 2003).

565 In this work, a set of fewer landmarks is acceptable or even desirable because there is a

566 large dataset that consists of only fossil material where in most of the cases the apex of the wing

567 is not preserved and the origin of the wing is usually neither preserved nor identifiable over the

568 ant body. Thus, a reduction in landmark number allows for more specimens to be included. In this

569 dataset, only 25 out of 399 wings are complete enough to assess a full set of 23 landmarks (Table

$570 \mathrm{~S} 2$ ). The shape variation in the cells $1-2 \mathrm{R}, 1 \mathrm{Rs}$, and $1 \mathrm{M}$ with 12 landmarks however, is sufficient

571 enough to discriminate between the types of Titanomyrma specimens but for a study among

572 different ant taxa, not all of the 12 landmarks may be assessable due to reduction of wing veins.

573 Using GM in the fossil record benefits from its versatility but relies on the complete set of

574 landmarks to be applicable. Twenty percent of the wings included could only be included because

575 of missing landmark estimation. Incorporating incomplete specimens not only enlarges sample

576 size, it also improved the results in contrast to removing incomplete specimens in studies with 
577 manufactured missing data (Arbour \& Brown, 2014). Out of the 36 wings that were problematic

578 in variation analyses (Table S3, from Fig 2 \& 3), 13 have missing values that were estimated.

579 That increased percentage is only based on a visual sample (Fig. 2 \& 3 ) but hints at a loss of

580 distinct venation characters, which especially affects the sexual shape dimorphism in T. gigantea

581 (Fig. 3A).

$582 \quad$ New insights into Titanomyrma

583 Lutz (1986) based the distinction between species T. gigantea and T. simillima on size and

584 characters in the wing venation, which can be made quantifiable using GM and the whole

585 spectrum of ants from Messel is covered with these two species. An allometric trend in Messel

586 can be observed that the smaller males have broader wings, which was not previously

587 acknowledged in studies that only considered crowding (Lutz, 1986, 1990; Wappler, 2003). Aside

588 from smaller shape differences, wing width, and size, males are characterised by a stout, almost

589 round gaster and a relatively large, pointy head with filiform antennae (Lutz, 1986). Females are

590 larger, have a narrower wing, a more lengthened gaster, and relatively short antennae (Lutz,

591 1986).

592 The sex dependent shape differences in T. gigantea are much smaller than the differences

593 between species. One of the most dominant factors in sexual difference is size, which is also

594 heavily supported by regression models. There is a trend that larger ants concentrate their first

595 medial, first radial, and first radial-sector cells in the centre of the wing which is called

596 "crowding" (Lutz, 1986, 1990). A stronger signal of allometry could separate the ants in shape

597 just according to their different sizes. However, Lutz (1986) observed that Titanomyrma males'

598 crowding values fit to those of the females despite being only about a third in size. The crowding

599 of wing cells $1-2 \mathrm{R}$ and $1 \mathrm{Rs}$ is species dependent. And so is the overall shape of the wing

600 venation.

601 When speaking of crowding, ants from Eckfeld showed similar distributions as ants in

602 Messel and by measuring the wings they could be incorporated into existing species (Wappler,

603 2003). Here, the relative sizes of the wing cells fit exclusively better to T. simillima.

604 Titanomyrma sp. from Eckfeld has its own shape pattern. Except for PE_1994_167-LS and a

605 somewhat reduced $r s-m$ no further affinities to $T$. giganteum could be ascertained for any of the

606 specimens included here according to GM. Males from Eckfeld do not seem to follow the

607 allometric trend as it is observable for males in Messel although also being considerably smaller

608 than their putative female counterpart, PE_1998_17-LS. However, to say that Titanomyrma sp. 
609 from Eckfeld does not exhibit a sexual shape dimorphism is difficult to assess as the female 610 sample size is too small for a thorough analysis.

611 Not only because of the smaller sizes and their similar shape, there is evidence to say that 612 except for PE_1994_167-LS and PE_1998_17-LS, all the specimens from Eckfeld are males.

613 Surprisingly, the first male genital apparatus of a Titanomyrma ant, PE_2000_3-LS, could be

614 described based on a specimen from Eckfeld distinguished by its large size relative to the 615 abdomen of the ant and its very detailed preservation (Wappler, 2003). Specimen PE_2000_3-LS

616 fits well within the normal shape scheme of male Eckfeld specimens. HLMD-Me-13500 from

617 Messel also provides genitalia and is very distinct from the Titanomyrma-genitalia described by

618 Wappler (2003). It could be determined as T. gigantea. Ironically, the genital apparatus of $T$.

619 gigantea evidently is much smaller than the one found in the Eckfeld specimen PE_2000_3-LS.

620 A male genital apparatus of T. simillima is still absent to prove a clear distinction between

621 Eckfeld and Messel beyond their shape differences.

622 The similarities in the "simillima-morphogroup" are probably due to symplesiomorphic 623 characters in wing venation and shape whereas the contractions of wing veins in T. gigantea may 624 represent a reduction from the original state. This inference can be drawn from evolutionary 625 reduction of the wing venation in ants and the comparison of simillima wing venation to other 626 ants with a generalized wing venation (Fig. 9, Brown \& Nutting, 1949; Perfilieva, 2010).

\section{Diversity within Titanomyrma}

The term "species" and higher ranks of taxonomy have of course inherent flaws as classifications are erected that reduce natural complexity and attempt to group relationships by certain criteria. This has been a problem in palaeontology as speciation in the fossil record has been a central discussion since the middle of the $20^{\text {th }}$ century (Sepkoski, 2016). Fossils have lost phylogenetic characters in comparison to their living progenitors so it is often hard to state a clear difference between differently aged specimens. Geometric Morphometrics reveals that there are informative morphological differences between all the Titanomyrma ants despite their similarity 635 at the first glance.

636 In many ant lineages, intraspecific cases of bimodal size variation are reported, especially 637 in females, which produced the term "queen-size-dimorphism" (QSD; Heinze \& Tsuji, 1995; 638 Wolf \& Seppä, 2016b). So far, no hypotheses have been made regarding T. gigantea and T. 639 simillima as polymorphic and conspecific although there is a bimodal size distribution. Causes 
640 for QSD are often attributed to alternative strategies of reproduction; e.g. larger queens, the

641 macrogynes, are better suited for founding colonies far off from their birthplace whereas the

642 microgynes settle near their birthplace or are even incorporated into their birth-colony (Heinze \&

643 Tsuji, 1995; Rueppell \& Heinze, 1999; Wolf \& Seppä, 2016b). Male size dimorphism is far less

644 common but when it appears, it may have the same causes as QSD and the two forms can overlap

645 (Fortelius et al., 1987; Elmes, 1991; Heinze \& Tsuji, 1995; Wolf \& Seppä, 2016a). In the Messel

646 sample, this could mean that there are simply two morphs for each sex belonging to a single

647 species that uses different reproductive strategies. However, the bimodality in size that is also

648 observable within Titanomyrma males is atypical (Rueppell, Heinze \& Hölldobler, 1998). Apart

649 from size and wing venation, there is no evidence for the subdivision of T. gigantea and T.

650 simillima into two different species (Lutz, 1986, 1990). A case concerning QSD in ant GM could

651 distinguish macrogynes and microgynes but not after size-relevant factors had been removed

652 (Perfilieva, 2007). As there is clear shape discrimination between T. gigantea and T. simillima

653 that also impacts male wing shape, GM analyses strongly support a two species interpretation. .

654 For the deposits of Eckfeld and Messel, there is a 5 Ma difference between the organisms

655 and theoretically, it would be possible that one of the species from Messel had survived over that

656 time, which would make most specimens from Eckfeld representatives of T. simillima due to their

657 similarities in shape. For some invertebrates, stasis has been reported and speciation events occur

658 in punctuated equilibria over an undisclosed amount of time (Benton \& Pearson, 2001). But

659 observations in the Formicidae, for example in Formica rufa C. Linnaeus, 1761 and relatives,

660 show that speciation can take place in a relatively short span lesser than $200 \mathrm{ka}$ (Goropashnaya,

661 Fedorov \& Pamilo, 2004). Given that the differences between males of T. simillima and males

662 from Eckfeld in their shape are easy to see in PCA and CVA, classifying Eckfeld specimens as $T$.

663 simillima is not advisable. A closer association with T. gigantea males has also been disproven

664 because wing shape is significantly different in the Eckfeld males despite ranging in the same

665 size. The significance of these characters in distinguishing a new species can be accepted as in

666 Titanomyrma, the wings are the most informative dividing factor. With PE_1998_17-LS, a second

667 species in Eckfeld is suggested that has to be treated with caution. It stands out in every aspect of

668 morphology but is singular and incomplete. For a final description of Eckfeld species, more

669 distinct characters such as the male genitals in PE_2000_3-LS should also be considered and

670 compared.

671 Lutz (1986) acknowledged the wing venation differences between F. brodiei and

672 Titanomyrma, but observed affiliations between males of T. simillima and F. brodiei due to size, 
673 which cannot be supported when analysing shape patterns. In fact, according to his

674 measurements, the F. brodiei holotype is the same size as Eckfeld and T. gigantea males. F.

675 brodiei and F. mirabile may be closer in shape to the Eckfeld specimens than to T. simillima .

676 Size is a relevant factor in distinguishing the giant ants and those specimens fit very well

677 together. The giant ants from England and Eckfeld should be compared regarding the expression

678 of $r s-m$ and M2. This task could be hard as Lutz $(1986,1990)$ noted heavy damages and

679 deformation for the holotypes of F. brodiei and F. mirabile. A reinvestigation using the original

680 fossils from the Bracklesham group is advisable to confirm the species status of the Eckfeld

681 specimens and as the two species F. brodiei and F. mirabile may even represent the male and

682 female of a single giant ant species (Lutz, 1986, 1990).

$683 T$. lubei from the Green River formation is very similar to T. simillima but is not 684 conspecific due to gaster shape (Archibald et al., 2011). No wing venation is recorded from $T$.

685 lubei and a larger set of specimens beyond the holotype will shed new light on the relationships

686 to the German giant ants. Currently, two new specimens with well-preserved spiracles and 687 anterior parts of the body are being investigated (pers. comm. Archibald 2017). As long as there 688 is no wing venation for T. lubei at hand, there is no possibility to investigate relationships to the 689 geographically closer F. berryi.

690

\section{GM for investigating ant relationships in deep time}

691

692

Reconstructing ant phylogeny based on morphology is difficult, in part due to convergent behavioural traits, such as seed harvesting and specialized predation, or homoplastic

693 morphological adaptations like polymorphic worker castes, so molecular phylogenies are valuable for shedding light on evolutionary relationships within ants (Hölldobler \& Wilson, 1990; Moreau et al., 2006; Ward, 2007; Arnan et al., 2012; Ward et al., 2015). While the practice

696 of utilizing shape patterns to reconstruct phylogenetic relationships has been critically reviewed

697 (De Meulemeester et al., 2012), it is becoming increasingly popular (Klingenberg \& Gidaszewski, 698 2010; Adams, Rohlf \& Slice, 2013).

699 Here, many fossil specimens could be included due to the thorough collecting work that 700 has been done in the Messel and Eckfeld fossil localities but in other analyses, far smaller sample 701 sizes are to expect. For bee fossils, GM has already been applied to trace taxonomic affinities and 702 diversity over time, despite the scarcity of available wing specimens (De Meulemeester et al., 703 2012; Wappler et al., 2012; Dehon et al., 2014, 2017). Singletons like F. brodiei or F. berryi do 
704 not offer the same thorough investigation possibilities like the larger number of specimens from

705 Messel and Eckfeld but in shape comparison to the others, affinities for F. brodiei to the Eckfeld-

706 morphogroup or a more stand-alone $F$. berryi are evidenced by GM so either way, the single

707 fossil is informative.

708 A properly formed ant wing is not a constant selective factor. This could result in high

709 wing-shape variability over the course of evolutionary history. The most extensive study on

710 patterns of ant wing venation in an evolutionary context was carried out by Perfilieva (2010) but

711 ant wing venation was found to be an unreliable phylogenetic character as any state of reduction

712 occurs in two or more subfamilies simultaneously. Nevertheless, ant wing-venation has been

713 proposed as a valuable morphological character and there are individual variations and trends at

714 the subfamily level (Brown \& Nutting, 1949; Klingenberg \& Dietz, 2004; Perfilieva, 2010). Our

715 results support the idea that wing venation in ants is an informative character to differentiate

716 groups and that the methods demonstrate potential to make use of fossil ant wings even when

717 preservation is incomplete.

718 With GM, palaeontology could be further incorporated into formicid evolutionary

719 research, especially to include valuable compression fossils that often only preserve isolated

720 wings. For example, several species of Cretaceous "armaniid" aculeate fossils from Russia and

721 Africa have been proposed as early members of Formicidae (Dlussky, 1975, 1983; Bolton, 2003).

722 However, because these taxa are known only from winged female imprint fossils, it has remained

723 impossible to confidently identify key synapomorphies typically utilized to place ant taxa (Engel

724 \& Grimaldi, 2005; LaPolla, Dlussky \& Perrichot, 2013). Because many of these armaniid fossils

725 preserve wing venation, it may be possible for GM to show affinities of these enigmatic taxa,

726 which in turn could significantly improve the understanding of early ant history. Studies that

727 incorporate GM could also aid in reinvestigating various interesting fossil ants that better

728 resemble extant ants, such as the large poneromorph queens from the Paleogene of Denmark

729 (Rust \& Andersen, 1999). The almost 100 specimens were assigned to the extant poneromorph

730 genus Pachycondyla F. Smith, 1858 because of strong similarities in the head but were revised to

731 the fossil myrmeciine genus Ypresiomyrma, also due to wing venation characters (Rust \&

732 Andersen, 1999; Archibald, Cover \& Moreau, 2006). A further GM analysis of such specimens

733 could be used to both reinvestigate previous attributions and trace ant evolutionary history in a

734 larger scale. 
735

736

737

738

739

740

741

742

743

744

745

746

747

748

749

750

751

752

753

754

755

756

757

758

759

760

761

762

763

764

765

766

\section{Position of Titanomyrma in the ant tree of life}

The relationships between Formiciinae and other subfamilies within Formicidae are enigmatic, primarily because the giant ants are quite unique. For example, the combination of a generalized wing venation pattern and a reduction of $r s-m$ as in T. gigantea was not observed in Perfilieva's (2010) study on wing venation but the shape is similar to formicoid ants that possess a reduced $M 3$.

The simillima-morphogroup has the most generalized wing venation pattern in the Formiciinae. Similarities to these giant ants occur for example in Amblyoponinae, Ponerinae, and Dolichoderinae (Fig. 9). Perfilieva (2010) observed a wing venation pattern like in the simillimamorphogroup only in Dolichoderinae and Ponerinae. The differences and similarities to these groups are probably describable and analysable by means of GM. The poneromorph representatives have a much larger relative size of the wing cells $1 \mathrm{M}, 1-2 \mathrm{R}$, and $1 \mathrm{Rs}$, of which the shape has been analysed here in Titanomyrma. The latter has been associated with these groups for quite some time as the outdated synonym Eoponera suggests (Carpenter, 1929). That synonym has only been revised rather recently by Lutz (1986). Since then, Titanomyrma has been argued to be a basal representative within the formicoid clade or sister taxon to the Formicinae (Lutz, 1986; Wappler, 2003).

Using the wing venation, the symplesiomorphic state of the simillima-morphogroup makes an internal phylogeny of Titanomyrma impossible. The phylogenetic position of Titanomyrma is unresolved and there is no possibility of a phylogeny based on wing venation alone as shown in other studies concerning wing venation (Michez et al., 2009; De Meulemeester et al., 2012; Wappler et al., 2012). However, affinities towards the dolichoderine wing venation pattern and others could be examined using GM (Fig. 9D). The current status of the Formiciinae as sister group to the Formicinae is solely based on the presence of a Furcula in female $T$. gigantea (Lutz, 1986). Additional useful phylogenetic characters are needed to place the Formiciinae (Grimaldi, Agosti \& Carpenter, 1997). Geometric morphometrics can be helpful in finding traits. For example, the sexual shape dimorphism pattern from T. gigantea and $T$. simillima also occurs in Formicinae, but was not observed in Myrmica (Perfilieva, 2007). Generalized ant wings should be further investigated with robust datasets and it would be desirable to create a dataset among formicid lineages and especially include more plesiomorphic sets of wing venation with a focus on shape to see if the Formiciinae may show more affinities to other ant groups in wing shape. 


\section{Palaeoecology}

Titanomyrma ants seem to show a surprising diversity on the taxonomic level as well as in

the few assumptions that can be made about ecology. T. gigantea dominates in Messel, representing $72 \%$ of all giant ant specimens. In Messel, only every fifth specimen is a male whereas in Eckfeld the males are absolutely dominant. In other deposits, the dominance of males or females cannot be assessed from the single wings but because of size, F. brodiei and F. berryi are also possibly males and $F$. mirabile is probably female. The only published ant from Green River, T. lubei is a female with the size of T. simillima (Archibald et al., 2011).

As the fossils represent a sample accumulated over a certain time, the different ratios of males to females in Messel and Eckfeld are reliable. However, interpreting those differences is highly speculative. Winged ants that accumulated and fossilized in water bodies in some distance to shores have been inferred to originate from mating swarms during nuptial flight (Rust \& Andersen, 1999). Ratios of males to females during nuptial flight are difficult to assess and they vary greatly between ant taxa and they can be subjected to intrinsic factors like ant size and extrinsic factors like vegetation, weather, time of the year, or altitude (Nagel \& Rettenmeyer, 1973; Franks et al., 1991; Lukasz, 2006; Wolf \& Seppä, 2016a). Behavioural explanations for a ratio like this would be that that giant ants in Messel relied on "female calling" and in Eckfeld on "male aggregation" syndromes (Wappler, 2003; Boomsma, Baer \& Heinze, 2005). Another source of different distribution could be that one of the sexes was the better flyer. A correlation of shape and an increased proportion in the sample is PC 2 in a PCA of SD 9 (see Fig. 2B). A narrower wing means more specimens. The ability of a larger ant to settle and fly farer from the birthplace compared to a smaller ant could explain a higher proportion of Titanomyrma females in the sample. Weight reconstructions in comparison with wing morphology imply that giant ants were poor flyers overall, which favoured falling into the steady water bodies and rapidly being fossilized (Wappler, 2003).

The Eocene gigantism also remains enigmatic in other ecological aspects. Reconstructed et al., 2011), but at present, there is not enough evidence to say that the Palaeocene-Eocene Thermal Maximum actually is the cause of gigantism (Verberk \& Bilton, 2011; Vermeij, 2016).

796 The giant ants had an Arctic dispersal with the additional finds from North America (Carpenter,

797 1929; Archibald et al., 2011). Other ecological assumptions concerning Titanomyrma are even 
798 more difficult, especially as workers are absent. The abundance of Titanomyrma in Messel is

799 outstanding but their size may prohibit a large colony or nest size although extant "giants" like

800 Dinomyrmex gigas (P.A. Latreille, 1802) do have multi-nest colonies of about 7000 inhabitants

801 (Lutz, 1986; Pfeiffer \& Linsenmair, 2000; Ward, Blaimer \& Fisher, 2010).

802

803

804

805

806

807

808

809

810

811

812

813

814

815

816

817

818

819

820

821

822

823

824

825

826

827

\section{Conclusions}

Geometric morphometrics, applied for fossil Titanomyrma specimens that are at least $50 \%$ complete in the section of the wing analysed here, reveals strong differences between groups. To investigate affinities between closely related ants based on their wing venation, several GM analyses are necessary because variation in the dataset is subtle and shape trends like a narrower wing in larger ants have an influence on the overall variation within the dataset. Creating subdatasets aids in finding visualizations and tracing the subtler differences.

Within the global dataset, LDA supports different groupings according to putative sex and species. A significant difference between all wings that have been described as species so far is observable. Moreover, all specimens that have been grouped in species are closer related to each other than to other giant ants and previously undetermined specimens are assignable using GM. The same applies to Titanomyrma sp. from Eckfeld where most specimens can be interpreted as belonging to a single species that is not yet described. Low variation makes sexual dimorphism in wing shape traceable to only some extent. Undetermined specimens from Messel are easily assigned to the species $T$. gigantea and T. simillima by analysing their wing shape. The results from the PCA are unambiguous and allow species determinations that represent Lutz's (1986) taxonomical criteria based on the wing venation. Titanomyrma wing venation is generalized. The most significant modifications occur in T. gigantea and this species provides the largest and bestpreserved dataset for future analyses. Shape similarities between T. simillima, F. brodiei, F. mirabile, F. berryi, and male Eckfeld Fomiciinae are possibly due to plesiomorphic venation conditions.

For Messel, it is quite remarkable that in a dataset of about 360 wings there are few outliers and that GM works well on two closely related species. Moreover, both species exhibit sexual dimorphism in the same features. Because of the reliability of the landmarks and the significant results, the methods of GM should be applied to gain insights into ant relationships from a morphological point of view. Titanomyrma wing venation should be analysed in context to 
828 other subfamilies within the Formicidae to investigate evolutionary patterns in ants and to further

829 illuminate the biology of the giant ants.

830

831

832

833

834

835

836

837

838

839

840

841

842

843

844

845

846

847

848

849

850

851

852

853

854

855

856

\section{Acknowledgements}

This is contribution no. 149 of the series Fossilfundstätte Eckfelder Maar (Mittel-Eozän).

We would like to thank Jes Rust (Bonn, DE) for reviewing the earliest versions of this

manuscript. The authors would like to Herbert Lutz (Mainz, DE) for access to collection material.

We greatly appreciate the help from Sonja Wedmann (Messel, DE) and Uta Kiel (Messel, DE)

from the Senckenberg Research Institute Frankfurt/ Main for access to collection material and preparation of photographies. We would like to thank Thorsten Plogschties (Bonn, DE) for help in preparing vector drawings of Titanomyrma wings. We would like to thank Ksenia Perfilieva (Moscow, RU) and two anonymous reviewers for helpful comments on an earlier draft of the manuscript. Additionally, Julian Katzke is grateful to Jes Rust for steady guidance during this work.

\section{Adams DC, Rohlf FJ, Slice DE. 2004. Geometric morphometrics: Ten years of progress} following the 'revolution'. Italian Journal of Zoology 71-(1):5-16 DOI $10.1080 / 11250000409356545$.

Adams DC, Rohlf FJ, Slice DE. 2013. A field comes of age: geometric morphometrics in the 21st century. Hystrix 24-(1):7-14 DOI 10.4404/hystrix-24.1-6283.

Arbour JH, Brown CM. 2014. Incomplete specimens in geometric morphometric analyses. Methods in Ecology and Evolution 5-(1):16-26.

Archibald SB, Cover SP, Moreau CS. 2006. Bulldog ants of the Eocene Okanagan Highlands and history of the subfamily (Hymenoptera: Formicidae: Myrmeciinae). Annals of the Entomological Society of America 99-(3):487-523 DOI 10.1603/00138746(2006)99[487:BAOTEO]2.0.CO;2.

Archibald SB, Johnson KR, Mathewes RW, Greenwood DR. 2011. Intercontinental dispersal of giant thermophilic ants across the Arctic during early Eocene hyperthermals. Proceedings of the Royal Society of London B: Biological Sciences 278-(1725):3679-3686 DOI 10.1098/rspb.2011.0729. 
857 Arnan X, Molowny-Horas R, Rodrigo A, Retana J. 2012. Uncoupling the effects of seed

858 predation and seed dispersal by granivorous ants on plant population dynamics. PloS ONE 7-

859 (8):e42869 DOI 10.1371/journal.pone.0042869.

860

Aytekin AM, Terzo M, Rasmont P, Çağatay N. 2007. Landmark based geometric

861 morphometric analysis of wing shape in Sibiricobombus Vogt (Hymenoptera Apidae: Bombus

862

863 Latreille). Annales de la Société Entomologique de France 43-(1):95-102 DOI

864

865

866

867 10.1080/00379271.2007.10697499.

Bai M, Ahrens D, Yang X-K, Ren D. 2012. New fossil evidence of the early diversification of scarabs: Alloioscarabaeus cheni (Coleoptera: Scarabaeoidea) from the Middle Jurassic of Inner Mongolia, China. Insect Science 19-(2):159-171 DOI 10.1111/j.17447917.2011.01460.x.

Barden P. 2017. Fossil ants (Hymenoptera: Formicidae): ancient diversity and the rise of modem lineages. Myrmecological News 24:1-30.

Barden P, Grimaldi DA. 2013. A new genus of highly specialized ants in Cretaceous Burmese amber (Hymenoptera: Formicidae). Zootaxa 3681:405-412 DOI 10.11646/zootaxa.3681.4.5.

Barden P, Grimaldi DA. 2014. A diverse ant fauna from the mid-Cretaceous of Myanmar (Hymenoptera: Formicidae). PloS ONE 9-(4):e93627 DOI 10.1371/journal.pone.0093627.

Barden P, Grimaldi DA. 2016. Adaptive radiation in socially advanced stem-group ants from the Cretaceous. Current Biology 26-(4):515-521 DOI 10.1016/j.cub.2015.12.060.

Baroni Urbani C, Bolton B, Ward PS. 1992. The internal phylogeny of ants (Hymenoptera: Formicidae). Systematic Entomology 17-(4):301-329.

Benton MJ, Pearson PN. 2001. Speciation in the fossil record. Trends in Ecology \& Evolution 16-(7):405-411 DOI 10.1016/S0169-5347(01)02149-8.

Bolton B. 2003. Synopsis and classification of Formicidae. Memoirs of the American Entomological Institute 71:1-370.

Bolton B. 2016. An Online Catalog of the Ants of the World. Available at https://www.antcat.org (accessed 29 July 2017).

Bonatti V, Simões ZLP, Franco FF, Francoy TM. 2014. Evidence of at least two evolutionary geometric morphometrics of forewings. Naturwissenschaften 101-(1):17-24 DOI 10.1007/s00114-013-1123-5.

Bookstein FL. 1997. Morphometric tools for landmark data: geometry and biology. Cambridge: Cambridge University Press. 
890

891

892

893

894

895

896

897

898

899

900

901

902

903

904

905

906

907

908

909

910

911

912

913

914

915

916

917

918

919

920

921

922

Boomsma JJ, Baer B, Heinze J. 2005. The evolution of male traits in social insects. Annual Review of Entomology 50:395-420 DOI 10.1146/annurev.ento.50.071803.130416.

Brady SG, Schultz TR, Fisher BL, Ward PS. 2006. Evaluating alternative hypotheses for the early evolution and diversification of ants. Proceedings of the National Academy of Sciences 103-(48):18172-18177 DOI 10.1073/pnas.0605858103.

Brown WL, Nutting WL. 1949. Wing venation and the phylogeny of the Formicidae (Hymenoptera). Transactions of the American Entomological Society 75-(3/4):113-132.

Carpenter FM. 1929. A fossil ant from the Lower Eocene (Wilcox) of Tennessee. Journal of the Washington Academy of Sciences 19:300-301.

Cockerell TDA. 1920. XXXVI._-Fossil Arthropods in the British Museum.- - I. Journal of Natural History 5-(27):273-279.

Csosz S, Seifert B, Müller B, Trindl A, Schulz A, Heinze J. 2014. Cryptic diversity in the Mediterranean Temnothorax lichtensteini species complex (Hymenoptera: Formicidae). Organisms Diversity \& Evolution 14-(1):75-88 DOI 10.1007/s13127-013-0153-3.

De Meulemeester T, Michez D, Aytekin AM, Danforth BN. 2012. Taxonomic affinity of halictid bee fossils (Hymenoptera Anthophila) based on geometric morphometrics analyses of wing shape. Journal of Systematic Palaeontology 10-(4):755-764 DOI 10.1080/14772019.2011.628701.

Dehon M, Michez D, Nel A, Engel MS, De Meulemeester T. 2014. Wing shape of four new bee fossils (Hymenoptera: Anthophila) provides insights to bee evolution. PloS ONE 9(10):e108865 DOI 10.1371/journal.pone.0108865.

Dehon M, Perrard A, Engel MS, Nel A, Michez D. 2017. Antiquity of cleptoparasitism among bees revealed by morphometric and phylogenetic analysis of a Paleocene fossil nomadine (Hymenoptera: Apidae). Systematic Entomology 42-(3):543-554 DOI 10.1111/syen.12230.

Dlussky GM. 1975. Superfamily Formicoidea Latreille, 1802. Family Formicidae Latreille, 1802. Trudy Paleontologicheskogo Instituta Akademiya Nauk SSSR 147:114-122.

Dlussky GM. 1983. A new family of Upper Cretaceous Hymenoptera: an 'intermediate link' between the ants and the scolioids. Paleontologicheskii Zhurnal 17:65-78.

Dlussky GM. 1999. The first find of the Formicoidea (Hymenoptera) in the Lower Cretaceous of the Northern Hemisphere. Paleontological Journal 33:274-277.

Dlussky GM, Rasnitsyn AP. 2002. Ants (Hymenoptera: Formicidae) of Formation Green River and some other Middle Eocene deposits of North America. Russian Entomological Journal 11:411-436. 
923 Elmes GW. 1991. Mating strategy and isolation between the two forms, macrogyna and

924 microgyna, of Myrmica ruginodis (Hym. Formicidae). Ecological Entomology 16-(4):411-

$925 \quad 423$ DOI 10.1111/j.1365-2311.1991.tb00234.x.

926 Engel MS, Grimaldi DA. 2005. Primitive new ants in cretaceous amber from Myanmar, New

927 Jersey, and Canada (Hymenoptera: Formicidae). American Museum Novitates 3485:1-24 DOI

928 10.1206/0003-0082(2005)485[0001:PNAICA]2.0.CO;2.

929 Fortelius W, Pamilo P, Rosengren R, Sundström L. 1987. Male size dimorphism and

930 alternative reproductive tactics in Formica exsecta ants (Hymenoptera, Formicidae). Annales

931 Zoologici Fennici 24:45-54.

932 Francoy TM, Grassi ML, Imperatriz-Fonseca VL, Jesús May-Itzá W de, Quezada-Euán

933 JJG. 2011. Geometric morphometrics of the wing as a tool for assigning genetic lineages and

934 geographic origin to Melipona beecheii (Hymenoptera, Meliponini). Apidologie 42-(4):499-

935507 DOI 10.1007/s13592-011-0013-0.

936 Franks NR, Sendova-Franks AB, Sendova-Vassileva M, Vassilev L. 1991. Nuptial flights and

937 calling behaviour in the ant Leptothorax acervorum (Fabr.). Insectes Sociaux 38-(3):327-330

938 DOI 10.1007/2FBF01314918.

939 Goropashnaya AV, Fedorov VB, Pamilo P. 2004. Recent speciation in the Formica rufa group

940 ants (Hymenoptera, Formicidae): inference from mitochondrial DNA phylogeny. Molecular

941 Phylogenetics and Evolution 32-(1):198-206 DOI 10.1016/j.ympev.2003.11.016.

942 Grimaldi DA, Agosti D. 2000. A formicine in New Jersey Cretaceous amber (Hymenoptera:

943 Formicidae) and early evolution of the ants. Proceedings of the National Academy of Sciences

944 97-(25):13678-13683 DOI 10.1073/pnas.240452097.

945 Grimaldi DA, Agosti D, Carpenter JM. 1997. New and rediscovered primitive ants

946 (Hymenoptera: Formicidae) in Cretaceous amber from New Jersey, and their phylogenetic

947 relationships. American Museum Novitates 3208:1-44.

948 Gunz P, Mitteroecker P, Bookstein FL, Weber GW. 2004. Computer-aided reconstruction of

949 incomplete human crania using statistical and geometrical estimation methods. In: Enter the

950 past: the e-way into the four dimensions of cultural heritage; CAA 2003; computer

951 applications and quantitative methods in archaeology; Proceedings of the 31st Conference,

952 Vienna, Austria, April 2003, 92-94.

953 Heinze J, Tsuji K. 1995. Ant reproductive strategies. Researches on Population Ecology 37-

$954 \quad(2): 135-149$. 
955 Higashi S, Yamauchi K. 1979. Influence of a supercolonial ant Formica (Formica) yessensis

956 Forel on the distribution of other ants in Ishikari Coast [Japan]. Japanese Journal of Ecology

957 29-(3):257-264 DOI 10.1007/BF02515814.

958 Hölldobler B, Wilson EO. 1990. The ants. Cambridge: Harvard University Press.

959 Hopkins MJ, Pearson JK. 2016. Non-linear ontogenetic shape change in Cryptolithus tesselatus

960 (Trilobita) using three-dimensional geometric morphometrics. Palaeontologia Electronica 19-

961 (3): $1-54$.

962 Kendall DG. 1977. The diffusion of shape. Advances in Applied Probability 9-(3):428-430 DOI $963 \quad 10.2307 / 1426091$.

964 Klingenberg C, Dietz BH. 2004. Ameisenflügel: morphologisches Merkmal zur

965 Gattungsbestimmung von drei neotropischen Triben mit Vorschlägen zur Nomenklatur.

966 Beiträge der Hymenopterologen-Tagung in Stuttgart:1-3.

967 Klingenberg CP. 2011. MorphoJ: an integrated software package for geometric morphometrics.

968 Molecular Ecology Resources 11-(2):353-357 DOI 10.1111/j.1755-0998.2010.02924.x.

969 Klingenberg CP. 2016. Size, shape, and form: concepts of allometry in geometric

970 morphometrics. Development Genes and Evolution 226-(3):1-25 DOI 10.1007/s00427-016-

$971 \quad 0539-2$.

972 Klingenberg CP, Gidaszewski NA. 2010. Testing and quantifying phylogenetic signals and

973 homoplasy in morphometric data. Systematic Biology 59-(3):245-261 DOI

$974 \quad 10.1093 /$ sysbio/syp106.

975 Lallensack JN, van Heteren AH, Wings O. 2016. Geometric morphometric analysis of

976 intratrackway variability: a case study on theropod and ornithopod dinosaur trackways from

977 Münchehagen (Lower Cretaceous, Germany). PeerJ 4:e2059 DOI 10.7717/peerj.2059.

978 LaPolla JS, Dlussky GM, Perrichot V. 2013. Ants and the fossil record. Annual Review of

979 Entomology 58-(1):609 DOI 10.1146/annurev-ento-120710-100600.

980 Lukasz D. 2006. Weather conditions during nuptial flight of Manica rubida (LATREILLE, 1802)

981 (Hymenoptera: Formicidae) in southern Poland. Myrmecologische Nachrichten 9:27-32.

982 Lutz H. 1986. Eine neue Unterfamilie der Formicidae (Insecta: Hymenoptera) aus dem mittel-

983 eozänen Ölschiefer der 'Grube Messel' bei Darmstadt (Deutschland, S-Hessen).

984 Senckenbergiana lethaea 67:177-218.

985 Lutz H. 1990. Systematische und palökologische Untersuchungen an Insekten aus dem Mittel986 Eozän der Grube Messel bei Darmstadt. Courier Forschungsinstitut Senckenberg 124:1-165. 
987

988

989

990

991

992

993

994

995

996

997

998

999

1000

1001

1002

1003

1004

1005

1006

1007

1008

1009

1010

1011

1012

1013

1014

1015

1016

1017

1018

Lutz H, Kaulfuss U, Wappler T, Loehnertz W, Wilde V, Mertz DF, Mingram J, Franzen JL, Frankenhaeuser H, Koziol M. 2010. Eckfeld maar: window into an Eocene terrestrial habitat in Central Europe. Acta Geologica Sinica 84-(4):984-1009 DOI 10.1111/j.17556724.2010.00237.x.

Maiorino L, Farke AA, Kotsakis T, Piras P. 2013. Is Torosaurus Triceratops? Geometric Morphometric Evidence of Late Maastrichtian Ceratopsid Dinosaurs. PloS ONE 8(11):e81608 DOI 10.1371/journal.pone.0081608.

Maiorino L, Farke AA, Kotsakis T, Piras P. 2015. Males resemble females: re-evaluating sexual dimorphism in Protoceratops andrewsi (Neoceratopsia, Protoceratopsidae). PloS ONE 10-(5):e0126464 DOI 10.1371/journal.pone.0126464.

Mertz DF, Renne PR. 2005. A numerical age for the Messel fossil deposit (UNESCO World Heritage Site) derived from $40^{\mathrm{Ar}} / 39^{\mathrm{Ar}}$ dating on a basaltic rock fragment. Courier Forschungsinstitut Senckenberg 255:67-75.

Mertz DF, Swisher CC, Franzen JL, Neuffer FO, Lutz H. 2000. Numerical dating of the Eckfeld maar fossil site, Eifel, Germany: a calibration mark for the Eocene time scale. Naturwissenschaften 87-(6):270-274 DOI 10.1007/s001140050719.

Michez D, De Meulemeester T, Rasmont P, Nel A, Patiny S. 2009. New fossil evidence of the early diversification of bees: Paleohabropoda oudardi from the French Paleocene (Hymenoptera, Apidae, Anthophorini). Zoologica Scripta 38-(2):171-181 DOI 10.1111/j.1463-6409.2008.00362.x.

Moreau CS, Bell CD. 2013. Testing the museum versus cradle tropical biological diversity hypothesis: phylogeny, diversification, and ancestral biogeographic range evolution of the ants. Evolution 67-(8):2240-2257 DOI 10.1111/evo.12105.

Moreau CS, Bell CD, Vila R, Archibald SB, Pierce NE. 2006. Phylogeny of the ants: diversification in the age of angiosperms. Science 312-(5770):101-104 DOI 10.1126/science. 112489 .

Nagel HG, Rettenmeyer CW. 1973. Nuptial flights, reproductive behavior and colony founding of the western harvester ant, Pogonomyrmex occidentalis (Hymenoptera: Formicidae). Journal of the Kansas Entomological Society 46-(1):82-101.

Perfilieva KS. 2000. Wing Venation Anomalies in Sexual Individuals of Ants (Hymenoptera, Formicidae) with Different Strategies of Mating Behavior. Entomological Review 80(9):1181-1188. 
1019

1020

1021

1022

1023

1024

1025

1026

1027

1028

1029

1030

1031

1032

1033

1034

1035

1036

1037

1038

1039

1040

1041

1042

1043

1044

1045

1046

1047

1048

1049

1050

1051

Perfilieva KS. 2007. Variability of quantitative characteristics of wings by the example of some ant species (Hymenoptera, Formicidae). Uspekhi Sovremennoi Biologii 127-(2):147-156.

Perfilieva KS. 2010. Trends in evolution of ant wing venation (Hymenoptera, Formicidae). Entomological Review 90-(7):857-870 DOI 10.1134/S0013873810070043.

Perfilieva KS. 2015. The evolution of diagnostic characters of wing venation in representatives of the subfamily Myrmeciinae (Hymenoptera, Formicidae). Entomological Review 95(8):1000-1009 DOI 10.1134/S0013873815080072.

Perrard A, Lopez-Osorio F, Carpenter JM. 2016. Phylogeny, landmark analysis and the use of wing venation to study the evolution of social wasps (Hymenoptera: Vespidae: Vespinae). Cladistics 32-(4):406-425 DOI 10.1111/cla.12138.

Perrichot V, Lacau S, Néraudeau D, Nel A. 2007. Fossil evidence for the early ant evolution. Naturwissenschaften 95-(2):85-90 DOI 10.1007/s00114-007-0301-8.

Perrichot V, Wang B, Engel MS. 2016. Extreme morphogenesis and ecological specialization among Cretaceous basal ants. Current Biology 26-(11):1468-1472.

Peters RS, Krogmann L, Mayer C, Donath A, Gunkel S, Meusemann K, Kozlov A, Podsiadlowski L, Petersen M, Lanfear R, others. 2017. Evolutionary history of the Hymenoptera. Current Biology 27-(7):1013-1018 DOI 10.1016/j.cub.2017.01.027.

Pfeiffer M, Linsenmair KE. 2000. Contributions to the life history of the Malaysian giant ant Camponotus gigas (Hymenoptera, Formicidae). Insectes Sociaux 47-(2):123-132 DOI 10.1007/PL00001690.

R Core Team. 2016. $R$ : A Language and Environment for Statistical Computing. Vienna.

Rohlf FJ. 1999. Shape statistics: Procrustes superimpositions and tangent spaces. Journal of Classification 16-(2):197-223 DOI 10.1007/s003579900054.

Rohlf FJ. 2015. The tps series of software. Hystrix 26-(1):9-12 DOI 10.4404/hystrix-26.111264.

Rohlf FJ. 2016a. tpsDig2. Department of Ecology and Evolution, State University of New York, Stony Brook.

Rohlf FJ. 2016b. tpsSmall. Department of Ecology and Evolution, State University of New York, Stony Brook.

Rohlf FJ. 2017. tpsUtil32. Department of Ecology and Evolution, State University of New York, Stony Brook.

Ross HH. 1936. The ancestry and wing venation of the Hymenoptera. Annals of the Entomological Society of America 29-(1):99-111 DOI 10.1093/aesa/29.1.99. 
1052 Rueppell O, Heinze J. 1999. Alternative reproductive tactics in females: the case of size 1053 polymorphism in winged ant queens. Insectes Sociaux 46-(1):6-17 DOI $1054 \quad 10.1007 / \mathrm{s} 000400050106$.

1055 Rueppell O, Heinze J, Hölldobler B. 1998. Size-dimorphism in the queens of the North 1056 American ant Leptothorax rugatulus (Emery). Insectes Sociaux 45-(1):67-77 DOI $1057 \quad 10.1007 / \mathrm{s} 000400050069$.

1058 Rust J, Andersen NM. 1999. Giant ants from the Paleogene of Denmark with a discussion of the 1059 1060 1061 1062 fossil history and early evolution of ants (Hymenoptera: Formicidae). Zoological Journal of the Linnean Society 125-(3):331-348 DOI 10.1111/j.1096-3642.1999.tb00596.x.

Rust J, Wappler T. 2016. Palaeontology: The Point of No Return in the Fossil Record of Eusociality. Current Biology 26-(4):R159 - R161 DOI 10.1016/j.cub.2016.01.038.

Schlager S. 2017. Package Morpho: Calculations and Visualisations Related to Geometric Morphometrics.

Seifert B, Yazdi AB, Schultz R. 2014. Myrmica martini sp. n.: a cryptic species of the Myrmica scabrinodis species complex (Hymenoptera: Formicidae) revealed by geometric morphometrics and nest-centroid clustering. Myrmecological News 19:171-183.

Sepkoski D. 2016. The "Species Concept" and the beginnings of paleobiology. In: Allmon WD, Yacobucci MM, eds. Species and speciation in the fossil record. Chicago, London: University of Chicago Press, 9-27.

Slice DE. 2007. Geometric morphometrics. Annual Review of Anthropology 36:261-281 DOI 10.1146/annurev.anthro.34.081804.120613.

Verberk WC, Bilton DT. 2011. Can oxygen set thermal limits in an insect and drive gigantism? PloS ONE 6-(7):e22610 DOI 10.1371/journal.pone.0022610.

Vermeij GJ. 2016. Gigantism and its implications for the history of life. PloS ONE 11(1):e0146092 DOI 10.1371/journal.pone.0146092.

Viscosi V, Cardini A. 2011. Leaf morphology, taxonomy and geometric morphometrics: a simplified protocol for beginners. PloS ONE 6-(10):e25630 DOI 10.1371/journal.pone.0025630.

Wappler T. 2003. Systematik, Phylogenie, Taphonomie und Paläoökologie der Insekten aus dem Mittel-Eozän des Eckfelder Maares, Vulkaneifel. Mainzer naturwissenschaftliches Archiv, Beiheft 27:1-234. 
1085 southwestern Germany (Hymenoptera Apidae). Systematic Entomology 37-(4):784-792 DOI $1086 \quad 10.1111 / \mathrm{j} .1365-3113.2012 .00642 . x$.

1087 Ward PS. 2007. Phylogeny, classification, and species-level taxonomy of ants (Hymenoptera: $1088 \quad$ Formicidae). Zootaxa 1668:549-563.

1089 Ward PS. 2014. The phylogeny and evolution of ants. Annual Review of Ecology, Evolution, and 1090 Systematics 45:23-43 DOI 10.1146/annurev-ecolsys-120213-091824.

1091 Ward PS, Blaimer BB, Fisher BL. 2016. A revised phylogenetic classification of the ant 1092 subfamily Formicinae (Hymenoptera: Formicidae), with resurrection of the genera 1093 Colobopsis and Dinomyrmex. Zootaxa 4072:343-357 DOI 10.11646/zootaxa.4072.3.4.

1094 Ward PS, Brady SG, Fisher BL, Schultz TR. 2015. The evolution of myrmicine ants: 1095 phylogeny and biogeography of a hyperdiverse ant clade (Hymenoptera: Formicidae). 1096 Systematic Entomology 40-(1):61-81 DOI 10.1111/syen.12090.

1097 Westwood JO. 1854. Contributions to fossil entomology. Quarterly Journal of the Geological 1098 Society 10-(1-2):378-396 DOI 10.1144/GSL.JGS.1854.010.01-02.43.

1099 Wilson EO. 1959. Some ecological characteristics of ants in New Guinea rain forests. Ecology 1100 40-(3):437-447 DOI 10.2307/1929761.

1101 Wolf JI, Seppä P. 2016a. Dispersal and mating in a size-dimorphic ant. Behavioral Ecology and 1102 Sociobiology 70-(8):1267-1276 DOI 10.1007/s00265-016-2135-x.

1103 Wolf JI, Seppä P. 2016b. Queen size dimorphism in social insects. Insectes Sociaux 63-(1):25110438 DOI 10.1007/s00040-015-0445-z.

1105 Yoshimura M, Fisher BL. 2007. A revision of male ants of the Malagasy region (Hymenoptera: 1106 Formicidae): Key to subfamilies and treatment of the genera of Ponerinae. Zootaxa 1654:21110740.

1108 Yoshimura M, Fisher BL. 2012. A revision of male ants of the Malagasy Amblyoponinae 1109 (Hymenoptera: Formicidae) with resurrections of the genera Stigmatomma and Xymmer. PloS 1110 ONE 7-(3):e33325 DOI 10.1371/journal.pone.0033325.

1111 Zelditch ML, Swiderski DL, Sheets HD. 2012. Geometric morphometrics for biologists: $a$ 1112 primer. London: Academic Press. 


\section{Figure 1}

Titanomyrma wing venation and landmarks

(A) Schematic drawing with venation nomenclature and cells considered in this study. The wing venation refers to specimen Mel1537, a female $T$. simillima. (B) The 12 landmarks used in this study digitalized onto specimen Mel10793 (Photo credit: Uta Kiel).
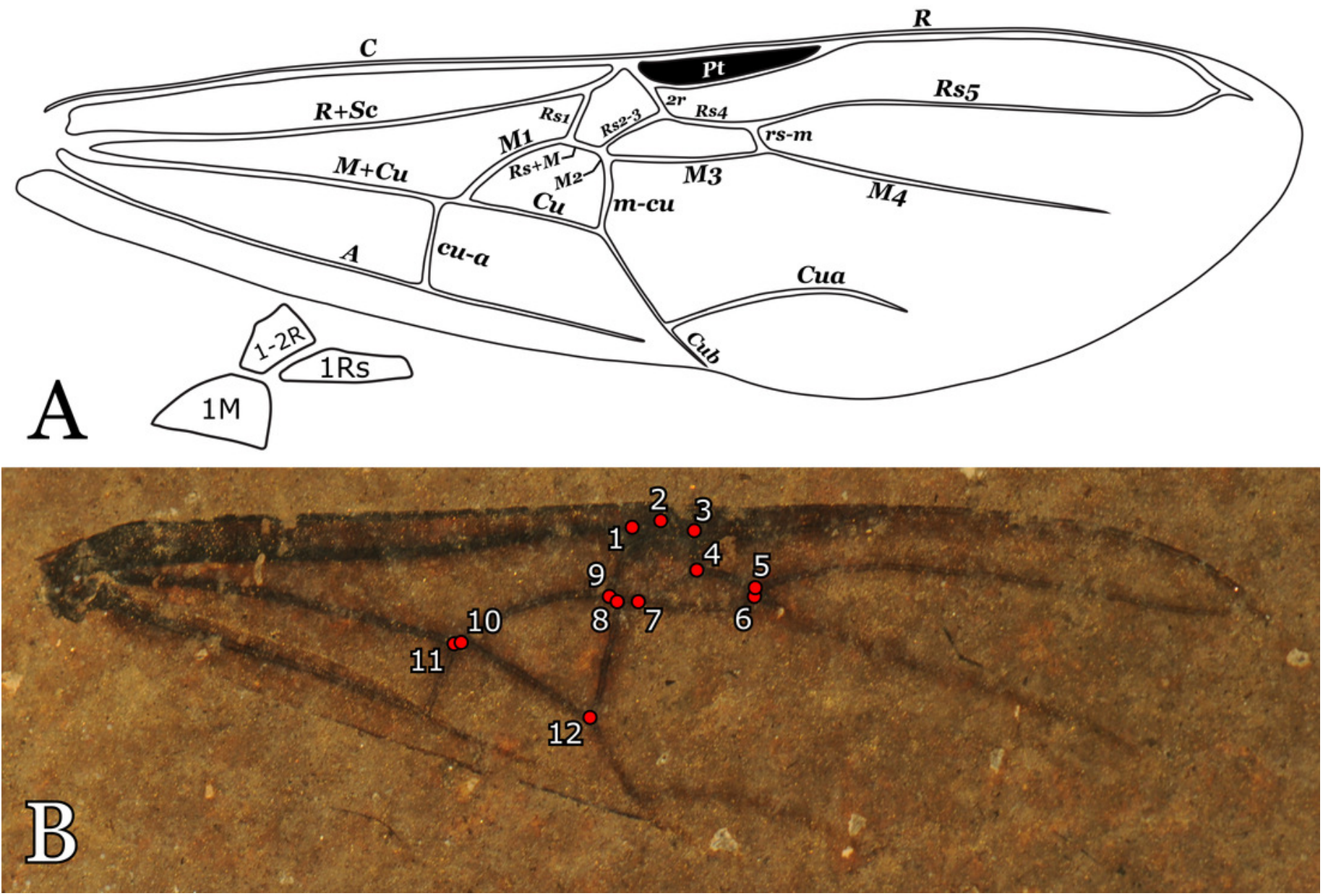


\section{Figure 2}

PCA of Titanomyrma specimens from Messel

The analysis was performed in SD3. (A) Wireframes represent the mean shapes of the respective species. High values in PC1 (58.31\%), where T. simillima clusters, signify the branching of $m$-cu farer off from $M 1$, more distance between $M 1$ and $c u-a$, a more pronounced rs- $m$, and larger relative sizes of cells 1-2R and 1Rs. Low values in PC1, where $T$. gigantea clusters, signify the opposite. Problematic specimens are marked with crosses (see Table S3). (B) High values in PC2 (13.60\%) mean a narrower wing in general, expressed by the shape shift of $L M 1,2,3$, and 12 . The lollipop graph dots indicate the mean shape of Titanomyrma specimens from Messel, lines stretch out in positive PC-value-shape change and end in with the value of 0.10 in PC2. 
A

$\underset{(13.60 \%)}{2}$

$0,10]$

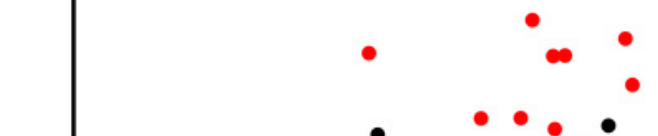

$0,05-$

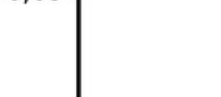

-

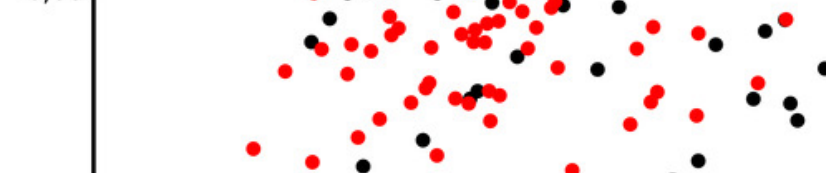

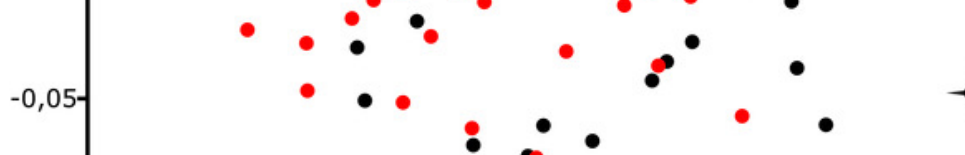

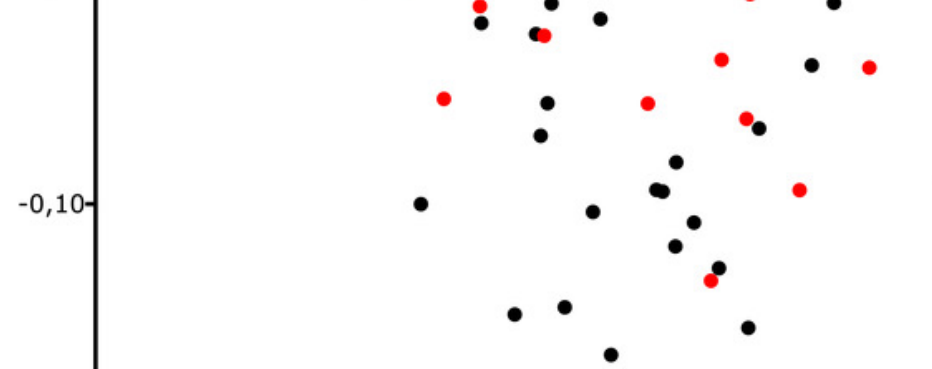

Titanomyrma gigantea Titanomyrma simillima

\section{Titanomyrma indet.}

MeI4060-MIR

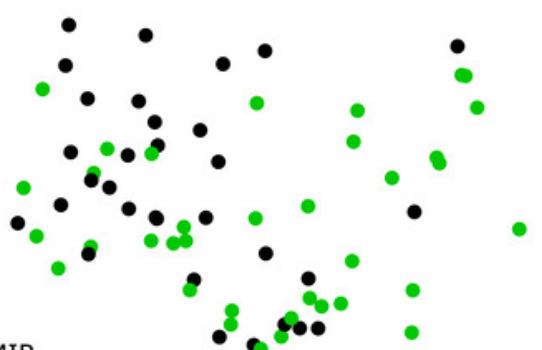

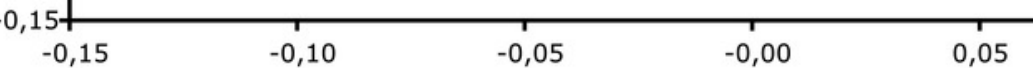
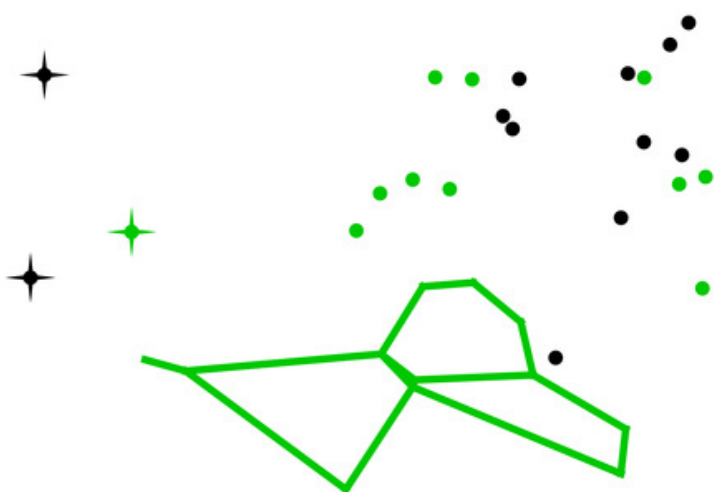

$20(58.31 \%)$

B<smiles>CCCCCCCCCCC(C)C</smiles>

2

$>10$

11

$\overbrace{8}^{9} 7$

PC 2

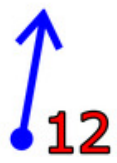




\section{Figure 3}

Shape patterns and variation between Titanomyrma females and males

In Titanomyrma, the sexes of the two described species share a common pattern of sexual shape dimorphism (A) Procrustes fitted mean shapes of $T$. gigantea females and males in comparison (SD7). The female shape is narrower than the male shape. (B) Procrustes fitted mean shapes of $T$. simillima females and males in comparison (SD8). The female shape is also narrower than the male shape. (C, D) Problematic specimens are marked with crosses (see Table S3). (C) A PCA of all 257 T. gigantea wings (SD7). The main variation does not well describe a shape separation between $T$. gigantea females and males. (D) A PCA of all $101 \mathrm{~T}$. simillima wings (SD8). Shape variation is more distinct for T. simillima females and males bur there is a severe outlier. 
A Titanomyrma gigantea B
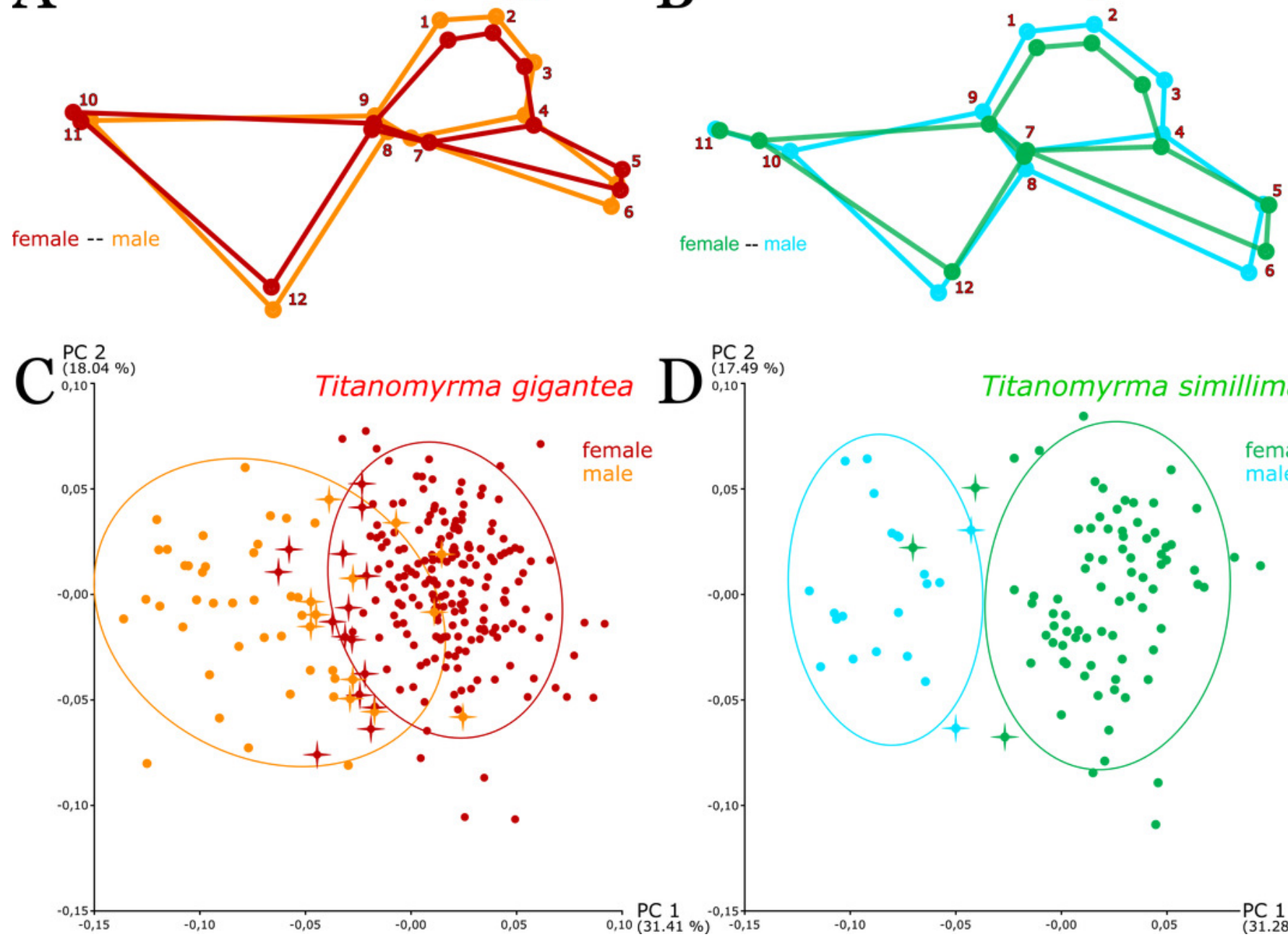

$\mathrm{PC} 2$
$(17.49 \%)$$\quad$ Titanomyrma simillima

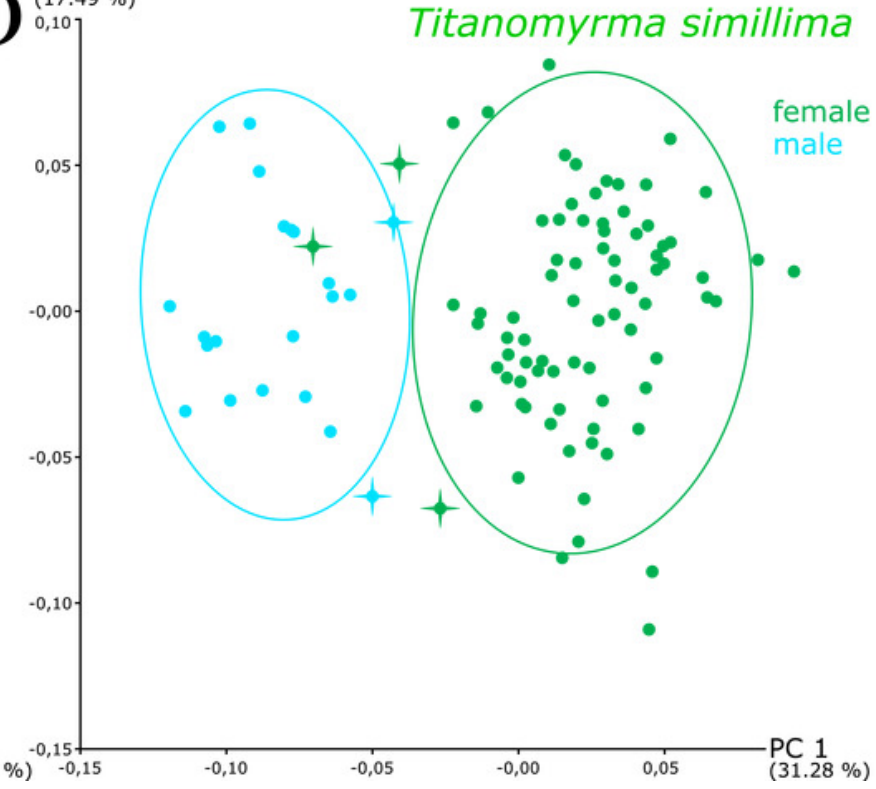




\section{Figure 4}

Shape and size variation among Titanomyrma and Formicium specimens

(A-C) Five larger Eckfeld males are highlighted with crosses. (A) A PCA of all specimens reveals close shape associations between Eckfeld specimens, $T$. simillima females, F. brodiei, and F. mirabile. F. berryi appears in an intermediate position. The overall pattern resembles the PCA of the Messel specimens (Fig. 2A). The analysis was performed in SD9. (B, C) The analyses were performed in SD10. (B) The independent variable Centroid Size is regressed over the dependent shape variable. T. gigantea is distinct in shape, signified by a higher Regression score. Eckfeld males and T. gigantea males have a similar size range. There is also a size overlap between Eckfeld males and T. simillima females. (C) A PCA including all specimens with scaling information, grouped after classifiers locality, species, and sex. This PCA was performed with the residuals of an attempt to correct for size by pooled-withingroup regression of shape over centroid size. Most of the variation is still between T. gigantea and the others. Female and male specimens cluster apart from each other in PC 2. 

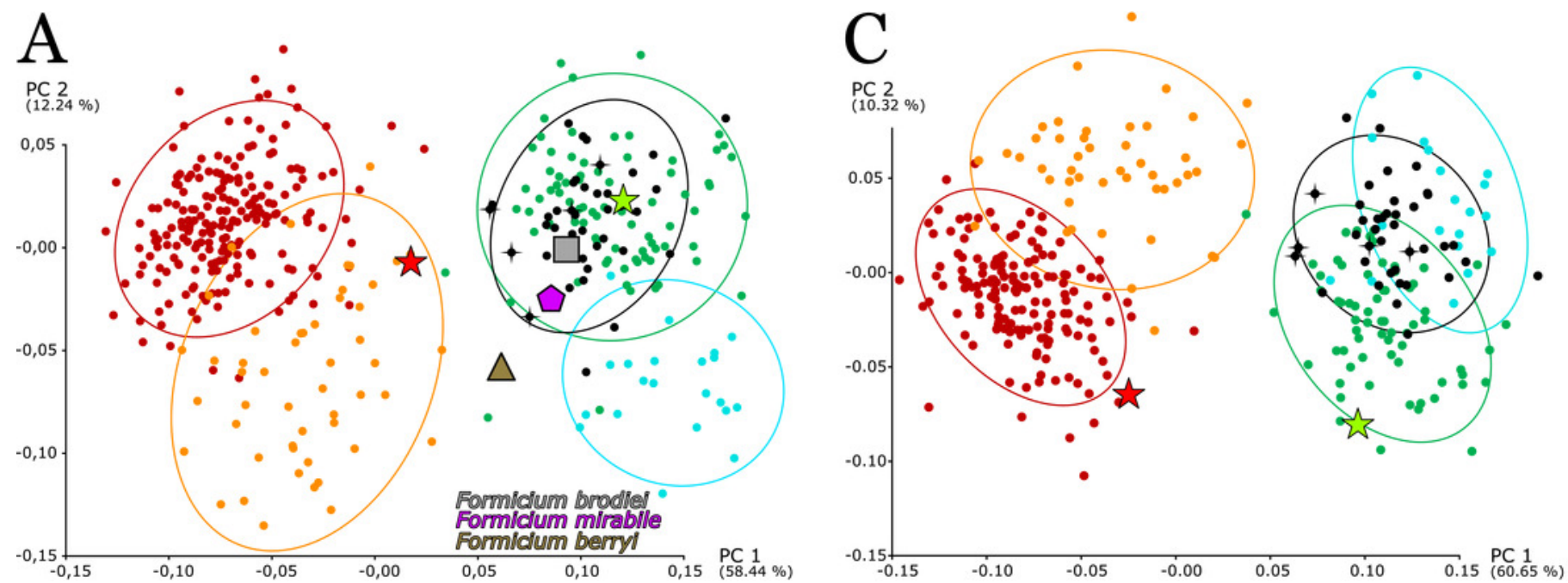

B

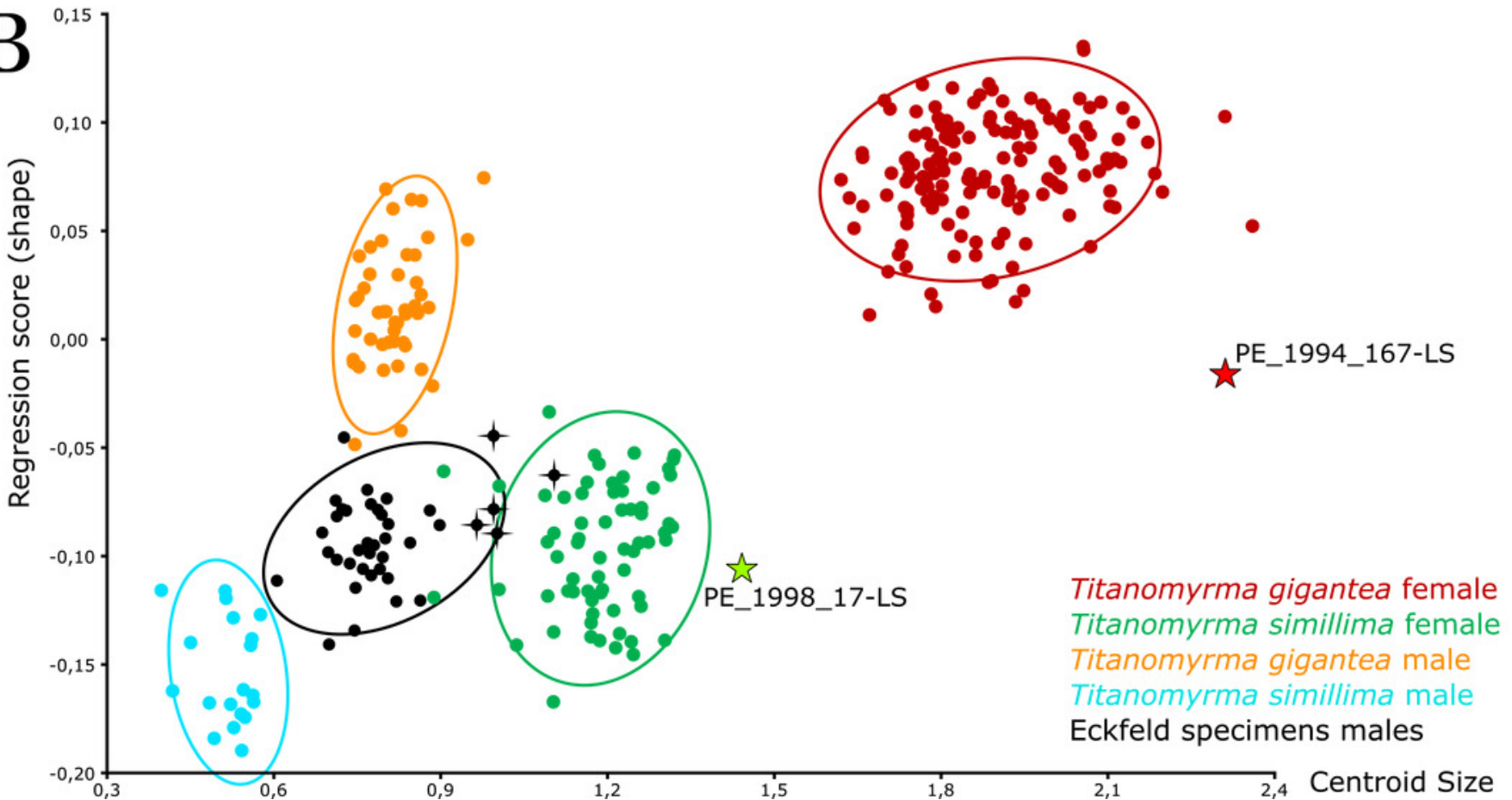




\section{Figure 5}

Titanomyrma and Formicium groups and individuals and their shapes

All Procrustes fitted shapes yielded from SD9. (A, B, D, E, G) Procrustes fitted mean shapes of Titanomyrma groups represented with more than one specimen. (C, F, G, I, K) Individual Procrustes fitted shapes of specimens with unique characteristics. PE_1994_167-LS (C) and PE_1998_17 (F) are specimens from Eckfeld that far exceed the size range of the rest of the specimens from Eckfeld (see Fig.4C). F. berryi $(\mathbf{H})$ is the only known giant ant wing with preserved venation from North America. F. brodiei $(\mathbf{I})$ and F. mirabile $(\mathbf{J})$ are specimens in the size range of a male $(26 \mathrm{~mm})$ and a female $(54 \mathrm{~mm})$ from Southern England. $(\mathbf{H}, \mathbf{I}, \mathbf{J})$ The shapes are based on landmarks digitalized onto interpretative drawings of the fossil specimens and must be taken with caution.

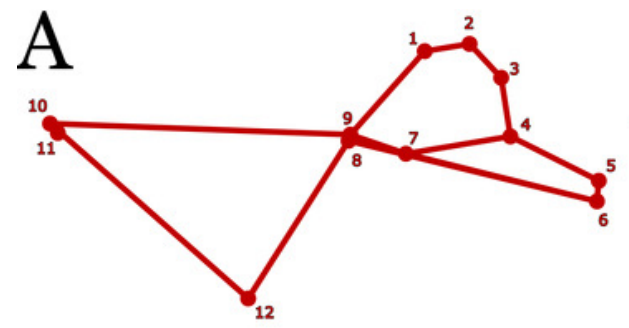

T. gigantea females (MS)

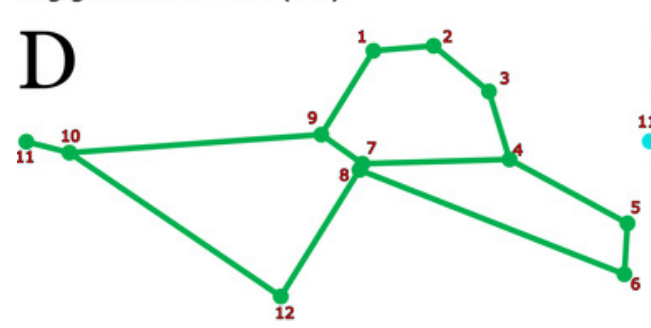

T. simillima females (MS)

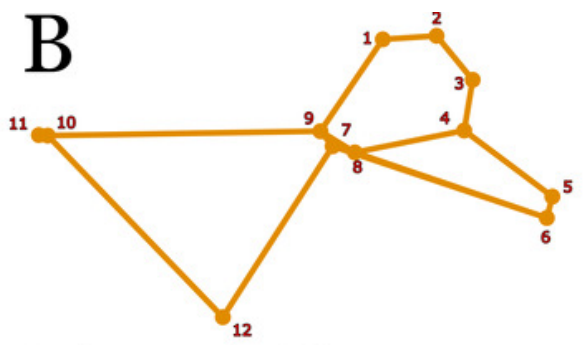

T. gigantea males (MS)

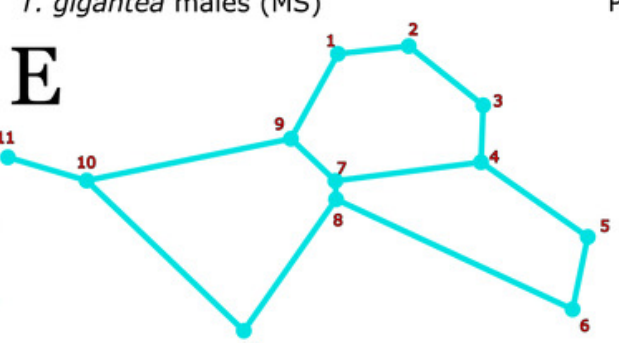

T. simillima males (MS)

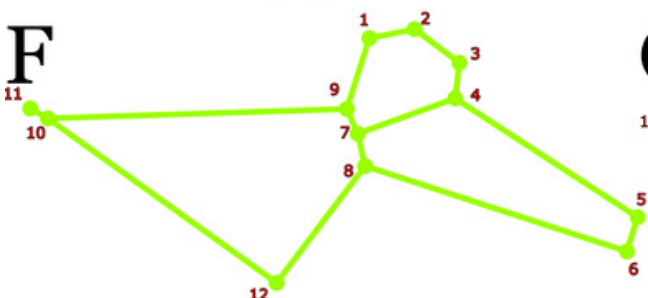

PE_1998_17-LS

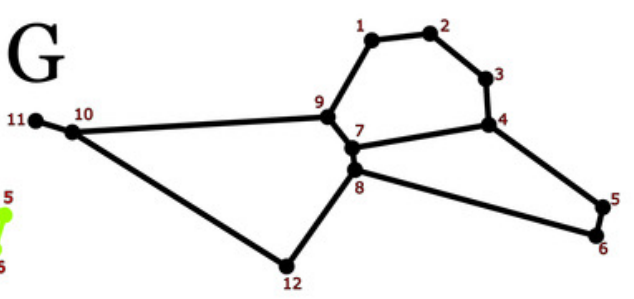

Eckfeld males (MS)

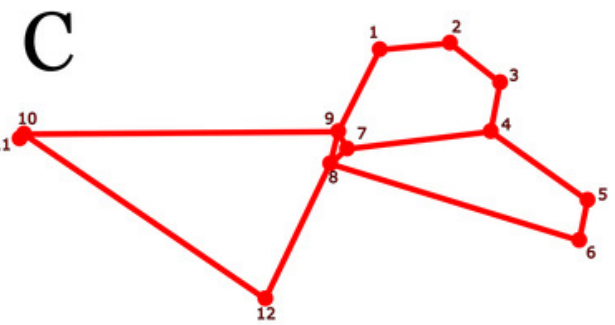

PE_1994_167-LS

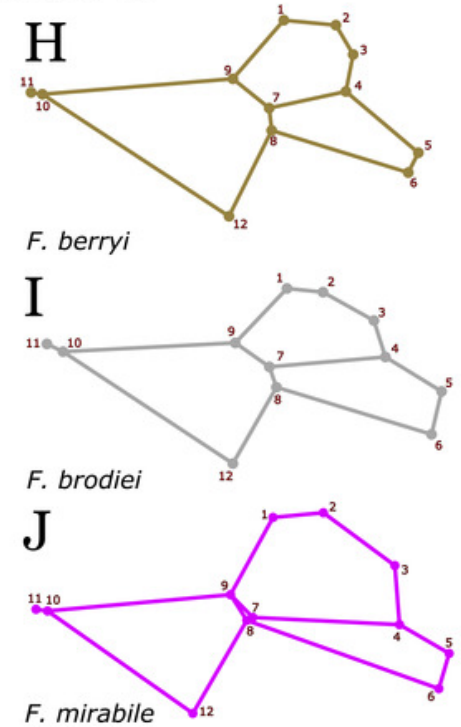




\section{Figure 6}

Shape analysis of the simillima-morphogroup

All analyses were performed to investigate the shape similarities and differences between Eckfeld speciemens (except for PE_1994_167, which is more similar to T. gigantea) and T. simillima. (A, B) Analyses were performed using SD9. Mean shapes of $T$. simillima females (A) vs. Eckfeld males and mean shapes of T. simillima males (B) vs. Eckfeld males. (B) Mean shapes of T. simillima males and Eckfeld females against each other. (C-F) Analyses were performed within SD 11. (C) PCA of the simillima-morphogroup separates T.simillima from the others in PC1 (26.55\%). (D) Low values in PC1, which separate T. simillima males, represent a cu-a more proximal to the ant body and relatively larger veins $R s+M$ and $r s-m$. (E) CVA of the simillima-morphogroup separates the Eckfeld males in in CV1 (55.06\%). A closer association of Eckfeld males with PE_1998_17-LS is indicated by the same loadings in CV1. (F) Differences between Eckfeld specimens and T. simillima are: $\mathrm{Cu}-\mathrm{a}$ and $\mathrm{M} 1 \mathrm{closer}$ together, $M 2$ well expressed, $r s-m$ more reduced. 

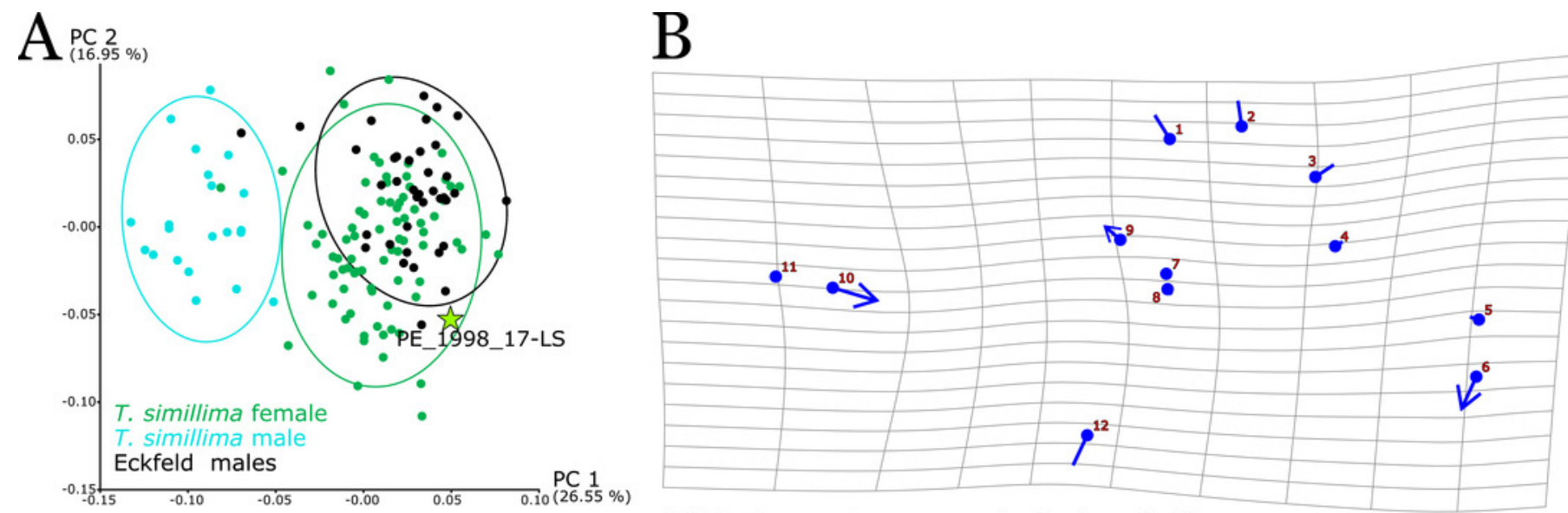

PC 1 shape change, scale factor -0.10

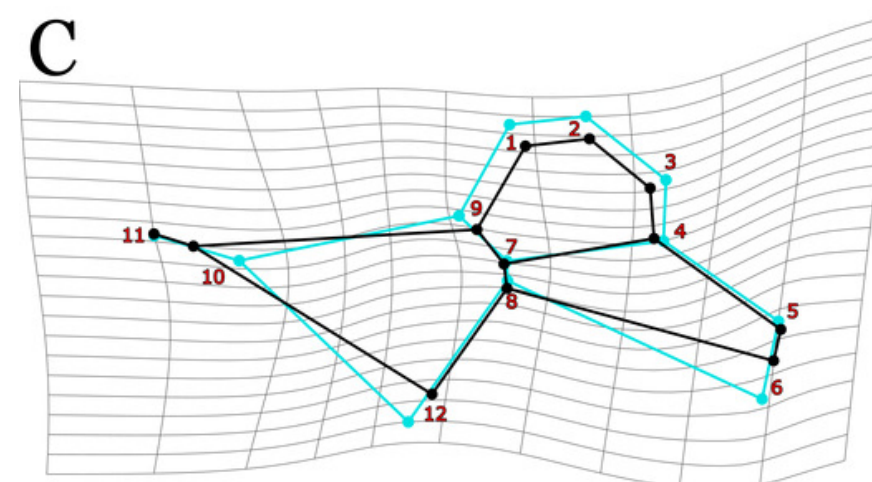

Eckfeld specimens males -- Titanomyrma simillima male

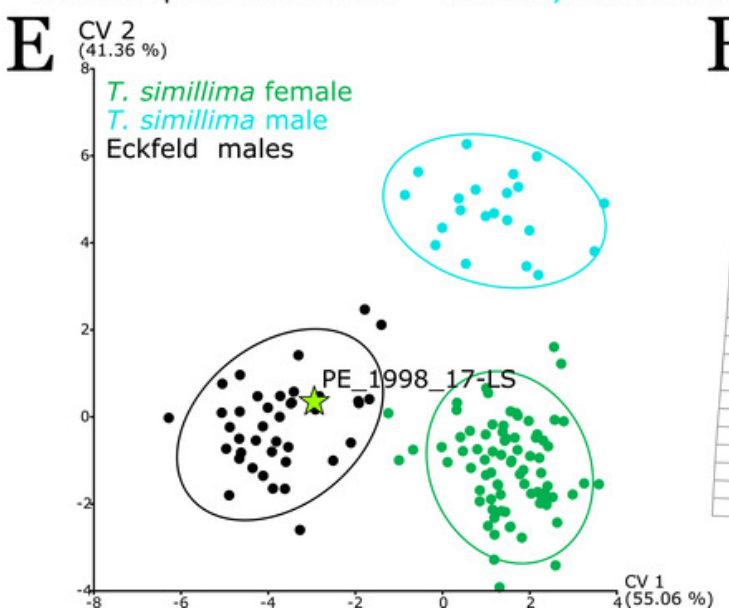

$\mathrm{F}$

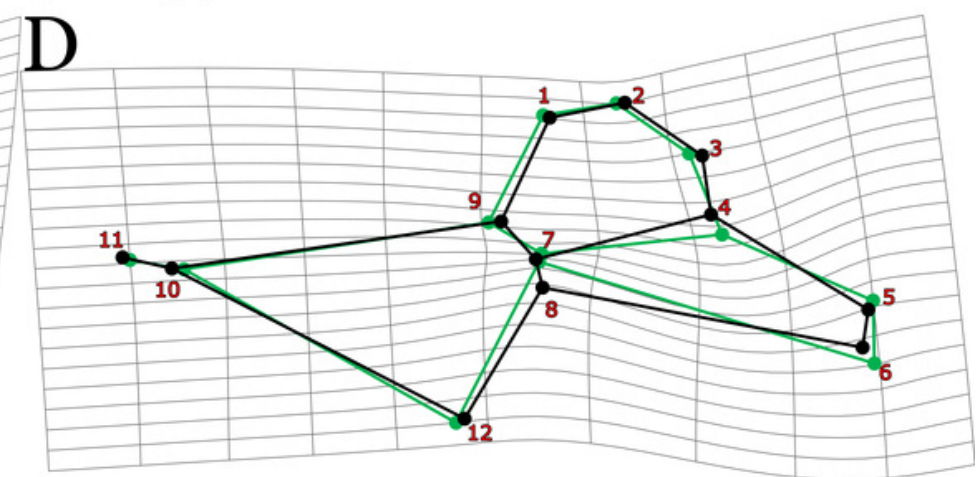

Eckfeld specimens males -- Titanomyrma simillima female

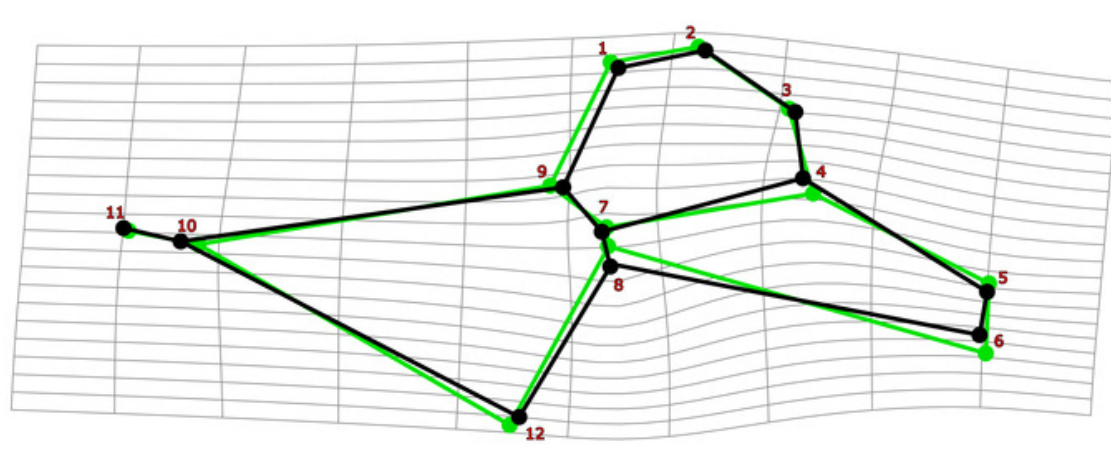

CV 1 shape change, scale factor -4 


\section{Figure 7}

Total and relative abundance of giant ants in different localities

(A) A count of all ants included in the dataset with two-wing specimens already halved for the count. (B) Relative abundance of different Titanomyrma types in Messel. (C) Relative abundance of different Titanomyrma types in Eckfeld.

A

\section{Groups}

1. Eckfeld males

2. PE_1994_167-LS

3. PE_1998_17-LS

4. F. berryi

5. F. brodiei

6. F. mirabile

7. T. gigantea females

8. T. gigantea males

9. T. simillima females

10. T. simillima males Eckfeld Messel
B Messel distribution [\%]

No. of Ants

33
1
1
1
1
1
187
42
74
21
35
324

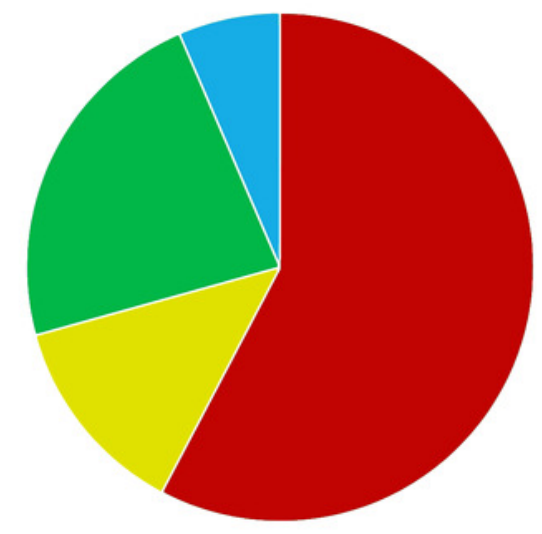

- T. gigantea females $=T$. gigantea males

- $T$. simillima females $=T$. simillima males
C Eckfeld distribution [\%]

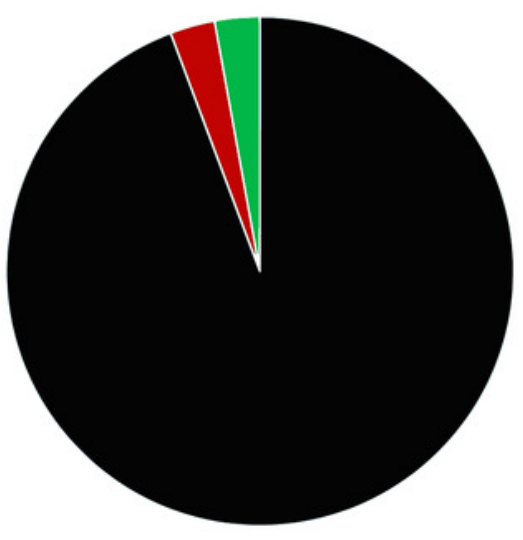

- Eckfeld males a PE_1994_167-LS - PE_1998_17-LS 


\section{Figure 8}

Twenty-three landmarks digitalized onto complete wings of $T$. gigantea specimens

(A) Specimen Mel12091 is a well-preserved female (Photo credit: Uta Kiel). (B) Specimen

Mel3362 is a well-preserved male with only the petioles and gaster missing (Photo credit: Uta Kiel). 


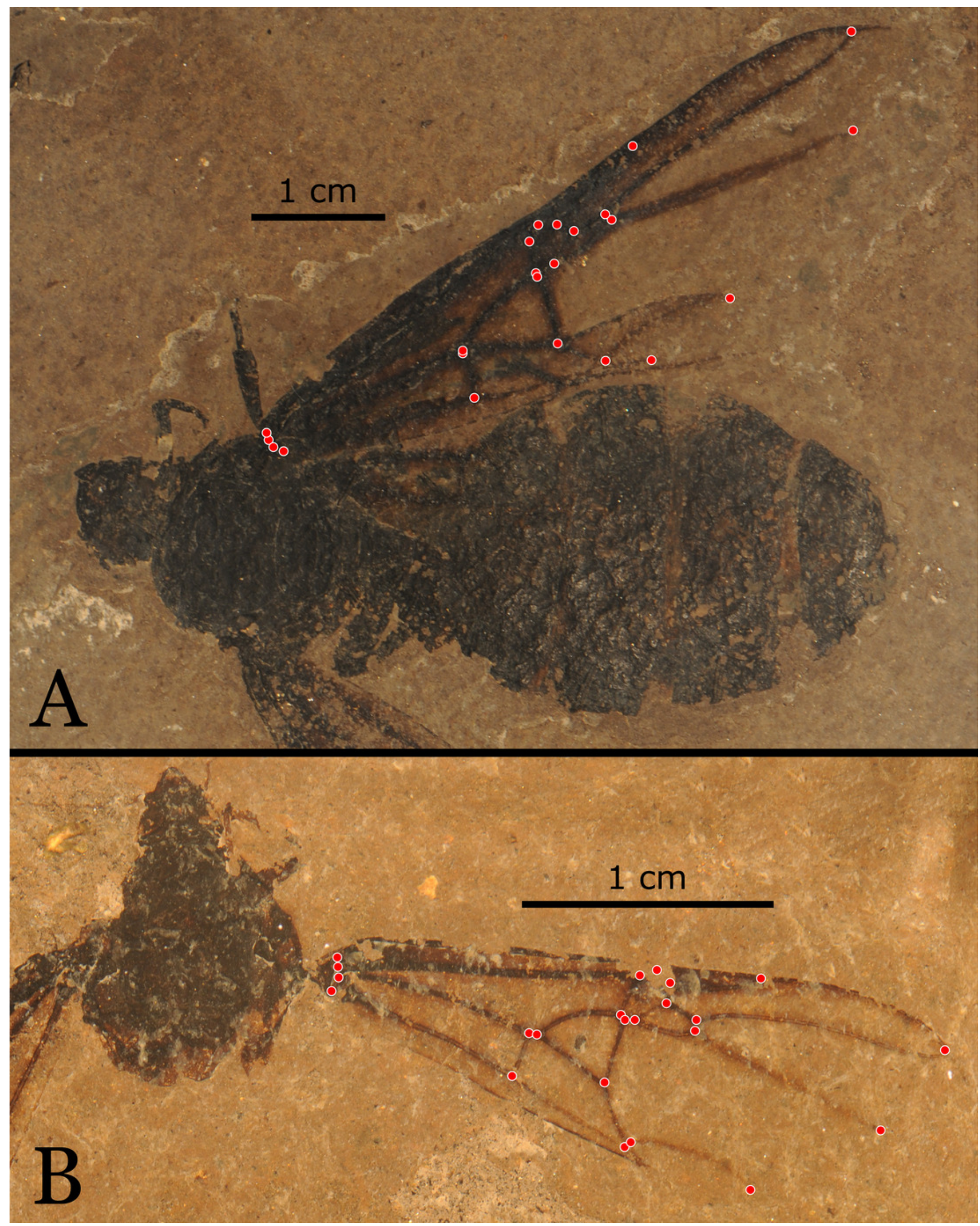




\section{Figure 9}

Generalized wing venation patterns in different ant taxa

Collection numbers starting with CASENT represents the California Academy of Sciences entomological collection based in San Francisco, CA. (A) Odontomachus coquereli J. Roger, 1861, subfamily Ponerinae (CASENT0049797; Photo credit: Erin Prado, available from www.antweb.org). (B) Mystrium rogeri A. Forel, 1899, subfamily Amblyoponinae (CASENT0001083; Photo credit: Cerise Chen, available from www.antweb.org). (C) The male F. simillimum specimen Mel14092. This specimen has been chosen due to its good preservation and because male $F$. simillimum have the most basal venation patterns with their well pronounced vein rs-m (Photo credit: Sonja Wedmann). (D) Dolichoderus debilis C. Emery, 1894, subfamily Dolichoderinae (CASENT0902952; Photo credit: Will Ericson, available from www.antweb.org).

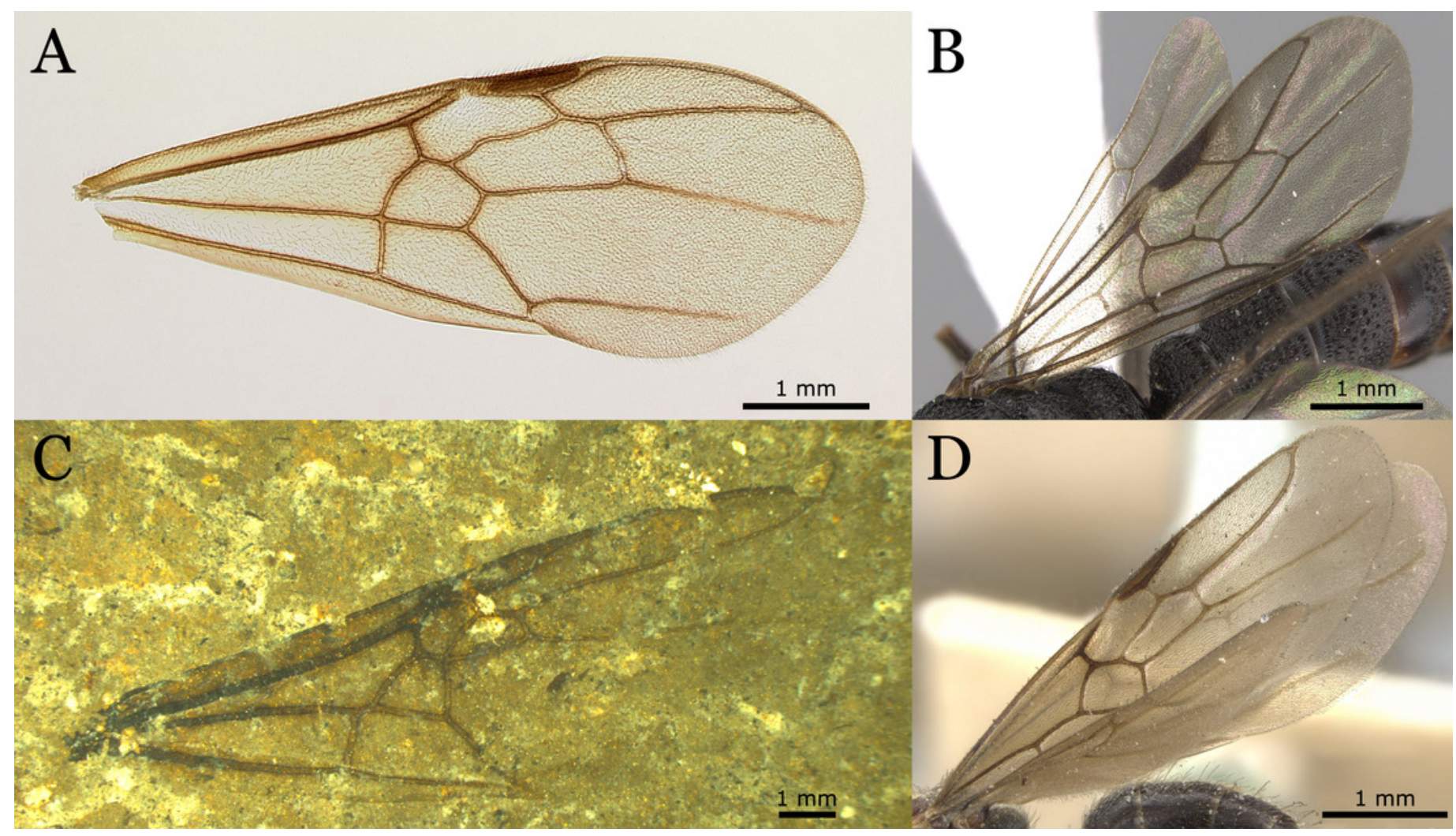




\section{Table $\mathbf{1}$ (on next page)}

Subdatasets used for the GM analysis

Subdatasets (SDs) were all created within MorphoJ out of the overall dataset consisting of 402 wings. Procrustes fits were performed for each SD. The only analyses performed with data generated from another analysis were done in SD6 and SD 10 after regression to investigate the sexual dimorphism in Titanomyrma ants. 


$\begin{array}{cc}\begin{array}{c}\text { Subdata- } \\ \text { set }\end{array} & \begin{array}{c}\text { No. of } \\ \text { wings } \\ \text { contained }\end{array}\end{array}$

SD 1

SD 2

SD 4

SD 5

SD 6

SD 7

SD 8

SD 9

SD 10

SD 11

SD 12

402

331

\section{Types of specimens}

contained

34 T. gigantea females

T. gigantea females, $T$.

46 gigantea males, $T$.

simillima females

358 all Messel specimens

257

all T. gigantea

101 all T. simillima

290

Messel specimens with scale

257 all T. gigantea

101

all T. simillima

141

all T. simillima, Eckfeld males, PE-1998-17

41 all Eckfeld specimens
Classifiers

used

Predetermined

Predetermined

Predetermined PCA

After species

assigned

After species

assigned

After full

assignment

After full

assignment

After full

assignment

After full

assignment

After full

assignment

After full

assignment

After full

assignment

\section{Manuscript to be reviewed}

LDA

PCA, CVA

\section{Analyses \\ performed}

PCA, CVA

(specimen, $\mathrm{l} / \mathrm{r}$

wing)

PCA

PCA

Regression, then: PCA, LDA

PCA

PCA

PCA, LDA

PCA, Regression, LDA

PCA, CVA,

Regression, LDA

\section{For investigating}

variability within

specimens

variability within specimens

shape discrimination between Messel species shape discrimination within T. gigantea shape discrimination within T. simillima sexual dimorphism in Messel species shape discrimination within T. gigantea shape discrimination within T. simillima shape discrimination between all specimens shape and size discrimination between all specimens

shape affinities within "simillimamorphogroup" shape affinities within the Eckfeld specimens 


\section{Table 2 (on next page)}

Wing venation patterns in Titanomyrma and Formicium groups and individuals

The observations are ranked from well-expressed $(++)$, over expressed $(+)$ and not expressed (-) to not expressed at all (- -). All observations from ++ to - - are in relation to the other groups and subjective. Crowding is measured by dividing the distance between crossings $R+S c / R s 1$ and $r s-m / M 4$ by the total length of the wing. Lower values indicate a more crowded wing. Reduction of M2 is not assessable in T. gigantea and PE_1994_167-LS due to the position of $m-c u$ before the branching of Rs2-3. 


\section{Manuscript to be reviewed}

\begin{tabular}{|c|c|c|c|c|c|c|c|}
\hline $\begin{array}{c}\text { Group } \\
\text { or individual }\end{array}$ & $\begin{array}{l}\text { Crow- } \\
\text { ding }\end{array}$ & $\begin{array}{c}\text { Approx. } \\
\text { size of } \\
\text { wing } \\
(\mathrm{mm})\end{array}$ & $\begin{array}{c}\text { Align- } \\
\text { ment of } \\
\text { M1, and } \\
\text { cu-a }\end{array}$ & $\begin{array}{c}\text { Align- } \\
\text { ment of } \\
\text { Rs1, M1, } \\
\text { Rs+M, } \\
\text { and } m-c u\end{array}$ & $\begin{array}{c}\text { Reduc- } \\
\text { tion of } \\
\text { M2 }\end{array}$ & $\begin{array}{l}\text { Reduc- } \\
\text { tion of } \\
r s-m\end{array}$ & $\begin{array}{l}\text { Wing } \\
\text { broad } \\
\text { or } \\
\text { narrow }\end{array}$ \\
\hline $\begin{array}{l}\text { T. gigantea } \\
\text { females }\end{array}$ & $++^{1}$ & $60^{1}$ & ++ & ++ & / & ++ & narrow \\
\hline $\begin{array}{l}\text { T. gigantea } \\
\text { males }\end{array}$ & $+^{1}$ & $27^{1}$ & ++ & + & / & ++ & broad \\
\hline $\begin{array}{l}\text { T. simillima } \\
\text { females }\end{array}$ & $--^{1}$ & $45^{1}$ & -- & - & ++ & - & narrow \\
\hline $\begin{array}{l}\text { T. simillima } \\
\text { males }\end{array}$ & $-{ }^{1}$ & $23^{1}$ & -- & -- & + & -- & broad \\
\hline Eckfeld males & varies $^{3}$ & 27 & - & -- & - & + & narrow \\
\hline $\begin{array}{c}\text { PE_1998_17- } \\
\text { LS }\end{array}$ & / & $>45$ & ++ & -- & -- & - & narrow \\
\hline $\begin{array}{c}\text { PE_1994_167 } \\
\text {-LS }\end{array}$ & / & $>60$ & + & ++ & / & - & narrow \\
\hline F. brodiei & $+^{1}$ & $26^{1}$ & - & -- & -- & -- & narrow \\
\hline F. berryi & $-{ }^{1}$ & $26^{1}$ & + & -- & -- & + & broad \\
\hline F. mirabile & $--^{2}$ & $54^{2}$ & + & - & + & - & narrow \\
\hline
\end{tabular}

${ }^{1}$ Lutz, 1986; ${ }^{2}$ Lutz, 1990; ${ }^{3}$ Wappler, 2003 